\title{
Chemical mechanisms in the dissolution kinetics of minerals; the aspect of active sites
}

\section{Dedicated to Werner Stumm for his $65^{\text {th }}$ birthday}

\section{Bernhard Wehrli, Erich Wieland and Gerhard Furrer ${ }^{1}$}

Swiss Federal Institute of Technology, Zurich (ETHZ) and Swiss Federal Institute for Water Resources and Water Pollution Control (EAWAG), CH-8600 Dübendorf

1 Department of Inorganic Chemistry, University of Bern, Freiestrasse 3, CH-3000 Bern 9

Key words: Weathering; dissolution; active sites; aluminum minerals; surface complex formation; surface structure.

\section{ABSTRACT}

Mechanistic rate laws for the description of mineral dissolution include (often implicitly) the mole fraction of active surface sites. The amount of active sites is first estimated by dissolution experiments in presence of polyvalent cations which inhibit proton-promoted dissolution. The dissolution reactivities of surface Al centers of several minerals and of comparable dissolved polynuclear $\mathrm{Al}$ complexes are determined. This comparison offers a second possibility for the indirect estimation of the concentration range of active surface sites. The coordination geometries of surface Al centers, which are given by the crystal lattice network, are considered to determine the reactivity in dissolution processes.

\section{Introduction}

Many minerals in nature which contribute to the chemical composition of the hydrosphere and soils are not in equilibrium with the aqueous phase. Where surface and soil waters are undersaturated with respect to a distinct mineral phase, the dissolution kinetics of that solid is of major interest.

The mechanisms of mineral dissolution kinetics have been a matter of controversy during the last decades. Three critical issues dominate the ongoing discussion: i) The dispute whether transport processes or surface reactions control feldspar weathering, ii) the question whether rate laws should be formulated in terms of dissolved species or surface species and iii) the role of dislocations, etch pits and active sites in dissolution kinetics.

Traditionally feldspar weathering was interpreted as being controlled by a protective surface layer. This kinetic model of a diffusion controlling depleted-layer was based on the observation of non-linear rate laws and non-stoichiometric dissolution processes (Correns and Von Engelhardt, 1938; Correns, 1963; Wollast, 
1967; Busenberg and Clemency, 1976). Only ten years ago, Holdren and Berner (1979) showed that this concept is probably based on experimental artifacts and that feldspar dissolution is controlled by surface reactions. They found that non-linear rate laws are caused by ultra fine particles which are produced during sample grinding. Because X-ray photoelectron spectroscopy gave no indication of a depleted layer, Holdren and Berner (1979) concluded that feldspar weathering is controlled by chemical surface reactions. Chou and Wollast (1985) investigated the dissolution kinetics of the same type of feldspar using a fluidized bed reactor. They found empirical rate laws with fractional orders in free proton and hydroxide ion concentration for the acidic and alkaline $\mathrm{pH}$ range, respectively. Using various new spectroscopic techniques Petit et al. (1987), Schott and Petit (1987) and Casey et al. (1988) have provided new evidence for depleted surface layers and for increased proton (water) content at the feldspar surface. Although these results sparked a new depleted-layer controversy, most authors now agree that dissolution of feldspar minerals, even if non-stoichiometric, often is controlled by slow chemical reactions occurring at mineral-water interfaces.

The mechanistic formulation of rate laws requires the knowledge of the structure and concentration of the reactive species. Based on the studies on oxide and hydroxide suspensions in aqueous solutions, Schindler and Kamber (1968), Stumm et al. (1970), Yates et al. (1974), Schindler et al. (1976), Davis et al. (1978), Westall and Hohl (1980), Kummert and Stumm (1980) and Sigg and Stumm (1981) proposed surface complexation models. These models build on both the tradition of coordination chemistry in homogeneous solutions and the electrical double-layer theory. The surface complexation models served as a starting-point for the study of the dissolution kinetics of oxides and hydroxides. Furrer and Stumm $(1983,1986)$, Pulfer et al. (1984) and Zinder et al. (1986) observed that dissolution kinetics of $\delta-\mathrm{Al}_{2} \mathrm{O}_{3}, \mathrm{BeO}, \gamma-\mathrm{Al}(\mathrm{OH})_{3}, \alpha-\mathrm{FeOOH}$ and $\alpha-\mathrm{Fe}_{2} \mathrm{O}_{3}$ are determined by distinct surface complexation reactions involving ligands and protons. These authors replaced the widely used empirical rate laws in terms of dissolved concentrations (see Chou and Wollast, 1985) by mechanistic rate laws involving directly the concentrations of chemical species at the solid-water interface. In other words, the concepts of surface complexation and dissolution kinetics have been linked successfully for simple oxides. Furrer and Stumm (1986), Stumm et al. (1987) and Wieland et al. (1988) developed a model for the proton-promoted dissolution. For $\delta-\mathrm{Al}_{2} \mathrm{O}_{3}$ and $\mathrm{BeO}$, they observed a third-order and second-order dependence of the dissolution rate on the surface proton concentration, respectively. This might lead to the question, whether the reaction order reflects the oxidation number of the cation in the oxide mineral or the number of surface ligands (see below) in the active sites. However, these probably coincidental results have not yet been confirmed by further studies. The experiments of Furrer and Stumm (1986) on the dissolution kinetics of $\delta-\mathrm{Al}_{2} \mathrm{O}_{3}$ in the presence of organic ligands have shown that (i) the rate of ligand-promoted dissolution is directly proportional to the concentration of adsorbed surface chelate complexes and (ii) that the adsorbed organic ligands have no effect on the proton promoted dissolution rates. Adsorbed anions and ligands which do not form a secondary phase are therefore probably not suitable for the inhibition of oxide dissolution. We show in this study that dissolution inhibitors can be found among the cations. 
Carroll-Webb and Walther (1988) dissolved corundum $\left(\alpha-\mathrm{Al}_{2} \mathrm{O}_{3}\right)$ in varying buffered aqueous solutions. They postulated the dissolution rates to be related to the first power of the surface proton concentrations for $\mathrm{pH}<8.5$ (this in contrast to the findings of Furrer and Stumm (1986) on $\delta-\mathrm{Al}_{2} \mathrm{O}_{3}$ ) and to the fourth power of the surface hydroxide ion concentration for $\mathrm{pH}>8.5$. Their conclusions, however, are based on a plot with a broad scatter in data, which makes the above mentioned rate orders rather uncertain.

Despite such experimental difficulties some workers tried to expand the simple coordination chemical approach to more complicated minerals. Blum and Lasaga (1988) published a reinterpretation of the kinetic study by Chou and Wollast (1985) on the dissolution of Amelia albite. They measured the surface protonation of the same mineral and were able to correlate the dissolution rates in the acidic and alkaline pH range with the surface concentration of protons and hydroxide ions, respectively. They found simple first-order dependencies of the reaction rate on the concentration of surface protons for $\mathrm{pH}<6$ and on the concentration of deprotonated surface groups for $\mathrm{pH}>7$, respectively. Amrhein and Suarez (1988) studied the dissolution kinetics of anorthite. Based on a best-fit argument they concluded that the reaction follows a mechanism with fourth order. Again, we think that this conclusion is based on relatively weak data. Looking a priori for a rate law with integer order, the authors ignored the possibility that two parallel mechanisms with different rate orders may occur. Guy and Schott (1989) reported the dissolution rates of a basalt glass in the acidic and alkaline $\mathrm{pH}$ range. They explained the slightly fractional rate orders of 3.8 and 3.7 with the mean valence of the network forming metals. However, the authors gave no mechanistic explanation of how the mean valence may enter a kinetic rate law. In summarizing this short review of recent studies on dissolution mechanisms we emphasize our scepticism: High quality data on both surface speciation and dissolution kinetics will be needed to resolve some of the contradictions in the literature.

Some of these conflicting experimental results may be due to the unknown role of active sites in weathering processes. Figure 1 presents the conventional kink and step model of active sites. It provides a conceptual framework for the relation between surface structure and reactivity. High resolution electron microscopy of feldspar grains at different stages of the weathering process indicates that the dissolution of some feldspars preferentially occurs along crystal defects induced by dislocations (Eggleton and Buseck, 1980). Crystal defects exert only slight effects on the thermodynamic properties of minerals, but they may considerably accelerate kinetic processes (Helgeson et al., 1984). Hence, the mole fraction of dissolution-active sites is usually considered in kinetic rate laws of dissolution reactions as an independent parameter (Aagaard and Helgeson, 1982). Various concepts have been suggested in order to quantify the morphological properties of mineral surfaces. Thereby, the ratio of dissolution-active to total sites is related either to the surface roughness (Helgeson et al., 1984), to the fractal dimension of a mineral grain (Avnir et al., 1985), to the morphology of etch pits (Blum and Lasaga, 1987) or to the activation energy of the dissolution reaction (Wehrli, 1989).

Recent experimental studies by Casey et al. (1988) and Schott et al. (1989) focused on the effect of crystal defects on weathering rates. In experiments carried out with a 
Wehrli, Wieland and Furrer

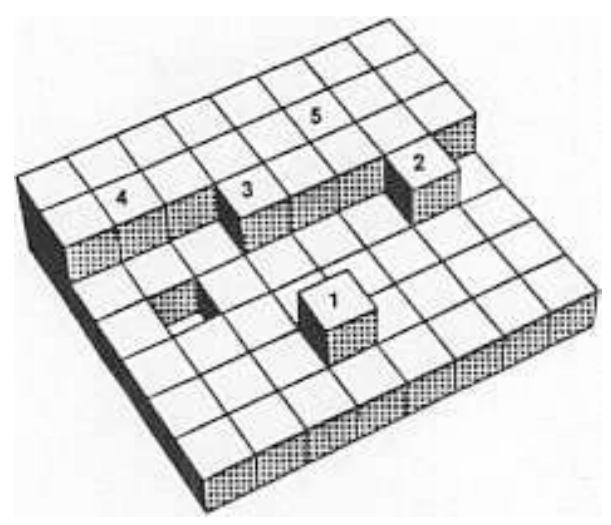

Figure 1. The step- and kink model of active sites. According to the number of surface bonds the following sites are distinguished: 1 Adatom, 2 ledge, 3 kink, 4 step, 5 face site. The rate of dissolution decreases from the very reactive adatoms to the inactive face sites

large variation in point defect densities $\left(>10^{5} \mathrm{~cm}^{-2}\right)$ the dissolution rate changed only by a factor of two, which is much less than predicted by the model of Blum and Lasaga (1987). The Monte Carlo simulations of Wehrli (1989), however, present evidence that the formation of steady-state morphologies might "override" the kinetic influence of point defects.

With this paper we would like to contribute to the ongoing controversy on the mechanisms of weathering. Most of the above cited papers deal with the role of adsorbed species such as protons and ligands in dissolution processes. Here we focus on the kinetic effects of distinct coordination geometries within the surface lattice. We first illustrate some of the complexities which arise in formulating dissolution mechanisms for anisotropic minerals such as kaolinite. We discuss how the surface protonation at distinct crystallographic planes effects mineral dissolution. Secondly we present experimental data which show that cations adsorbed on the surface inhibit the weathering process of a mineral. Based on probability arguments, we derive a kinetic rate law which accounts for the blocking effect of cations during dissolution processes. Inhibition experiments allow us to estimate the concentration of dissolution active sites. Finally we propose a new approach to deduce structural and kinetic constraints on the concentration of active sites. We compare decomposition rates of structurally well defined polynuclear species with dissolution rates. The $\mathrm{Al}_{13}$ polynuclear complex lends itself as a kinetic bench mark species, because the $\mathrm{Al}$ centers in $\mathrm{Al}_{13}$ exhibit a similar coordinative environment as step sites on aluminum oxides.

\section{Materials and methods}

\section{Dissolution of kaolinite}

To achieve a homogeneous kaolinite surface, the highly crystalline Cornish clay ("China Clay Supreme") was pre-treated by soaking in dilute $\mathrm{HNO}_{3}(\mathrm{pH}=1.5)$ for 
two days. After rinsing several times with distilled water, coarse and fine fractions were removed through sedimentation in alkaline solution followed by centrifugation $(10 \mathrm{~min}$ at $5000 \mathrm{rpm})$. The kaolinite was subsequently washed in ethanol and dried at $110^{\circ} \mathrm{C}$. The BET surface area was $15.3 \pm 0.77 \mathrm{~m}^{2} / \mathrm{g}$. Prior to dissolution experiments, the kaolinite suspensions were "conditioned" by pre-exposing them for four days in a medium similar to that used in the experiments. The suspensions then were centrifuged and the residual solids resuspended in the reaction medium. All dissolution experiments were carried out at $25^{\circ} \mathrm{C}$ in $0.1 \mathrm{M} \mathrm{NaNO}_{3}$ with $5 \mathrm{~g} / \mathrm{l}$ kaolinite. The $\mathrm{pH}$ was controlled and corrected daily in case of slow dissolution reactions or automatically corrected with the aid of a titrator. The chemical analysis of the solution were performed by the following method: silica by colorimetric measurements after reduction of silica-molybdate complex with ascorbic acid, and dissolved $\mathrm{Al}$ by electrothermal atomic adsorption.

\section{The blocking of active sites on $\delta-\mathrm{Al}_{2} \mathrm{O}_{3}$ by the vanadyl ion}

The preparation of $\mathrm{VO}^{2+}$ is described by Wehrli and Stumm (1989). Suspended $\delta$ $\mathrm{Al}_{2} \mathrm{O}_{3}$ (Aluminiumoxid $\mathrm{C}$, Degussa) was soaked in $\mathrm{HF} / \mathrm{H}_{2} \mathrm{SO}_{4}$ solution (1 $\mathrm{M}$ and $0.15 \mathrm{M}$, respectively) for 1.5 hours. The suspension was washed once with $0.04 \mathrm{M} \mathrm{H}_{2} \mathrm{SO}_{4}$ and subsequently several times with distilled water. The BET surface area of the pre-treated $\delta-\mathrm{Al}_{2} \mathrm{O}_{3}$ was obtained as $96 \pm 5 \mathrm{~m}^{2} / \mathrm{g}$. Prior to dissolution experiments, the $\delta-\mathrm{Al}_{2} \mathrm{O}_{3}$ suspensions $(1.5 \mathrm{~g} / \mathrm{l})$ were conditioned by pre-exposing them for three days in a $\mathrm{VO}^{2+}$-free medium similar to that used in the subsequent experiments $\left(\mathrm{pH}=3, I=0.1 \mathrm{MNaNO}_{3}\right.$ and $\left.T=25^{\circ} \mathrm{C}\right)$. After centrifuging the suspension, the solid phase was resuspended. In the absence of $\mathrm{O}_{2}\left(\mathrm{~N}_{2}\right.$-bubbling) and at $\mathrm{pH} 4.5$, various amounts of $\mathrm{VO}^{2+}$ stock solution were slowly added to the suspension. After equilibrating for two hours, the suspension was acidified to $\mathrm{pH} 3$ and the volume adjusted to $50 \mathrm{ml}$. The $\mathrm{pH}$ was controlled by means of an automatic titrator which replaced the protons (as $\mathrm{HNO}_{3}$ ) used up in the dissolution experiments. Total vanadium ( $\mathrm{VO}^{2+}$ in the absence of oxygen) and $\mathrm{Al}$ released from the surface were analyzed by electrothermal atomic adsorption.

\section{Decomposition kinetics of $A l_{13}$}

Solutions of the $\mathrm{Al}_{13}$ polynuclear species $\left(\mathrm{Al}_{13} \mathrm{O}_{4}(\mathrm{OH})_{24}\left(\mathrm{H}_{2} \mathrm{O}\right)_{12}^{7+}\right)$ were synthesized as follows from reagent grade chemicals: In the experiments of series $\mathrm{A}$ a $50 \mathrm{ml}$ titration vessel with water-jacket was kept at $50^{\circ} \mathrm{C}$ with a thermostat. A degassed mixture of $25 \mathrm{ml}$ of $2 \mathrm{M} \mathrm{NaCl}$ solution, $2 \mathrm{ml} 0.125 \mathrm{M} \mathrm{AlCl}_{3}$ solution and $18 \mathrm{ml}$ bidistilled water was prepared and equilibrated under nitrogen. Within 30 minutes $5 \mathrm{ml}$ of $0.1 \mathrm{M} \mathrm{NaOH}$ (Baker Dilute-It) were slowly added from a burette under continuous magnetic stirring. The solution was then equilibrated for an additional hour, and cooled to $25^{\circ} \mathrm{C}$ within the next $30 \mathrm{~min}$. The final solution was $5 \mathrm{mM}$ in total $\mathrm{Al}$ with a ratio of bound hydroxide ions of $\left[\mathrm{OH}^{-}\right]_{b} /[\mathrm{Al}]_{t}=2.0$. The rather low ratio was chosen in order to avoid further polymerization and precipitation. This was very important in the experiments of series $B$ which followed the same procedure but 
with $50 \mathrm{mM}[\mathrm{Al}]$, neutralized by $1 \mathrm{M} \mathrm{NaOH} .{ }^{27} \mathrm{Al}-\mathrm{NMR}$ measurements confirmed that $\mathrm{Al}_{13}$ was the dominant aluminum species in the solutions prepared by this procedure. Each synthesis was immediately followed by the kinetic experiment in which temperature and ionic strength were kept constant at $25^{\circ} \mathrm{C}$ and $I=1.0 \mathrm{M} \mathrm{(NaCl)}$. The $\mathrm{pH}$ was adjusted by adding a solution of $0.1 \mathrm{M} \mathrm{HCl}$ in $0.9 \mathrm{M} \mathrm{NaCl}$ (series A) or $1 \mathrm{M} \mathrm{HCl}$ (series B) from an automatic burette connected via a titrator to a $\mathrm{pH}$-meter (Radiometer). The apparatus was set in the $\mathrm{pH}$-stat mode and the consumption of $\mathrm{HCl}$ monitored over time. At periodic time intervals $\mathrm{pH}$ and burette readings were recorded and the concentrations of bound hydroxide, $\left[\mathrm{OH}^{-}\right]_{b}$, were calculated.

\section{Anisotropic dissolution}

\section{Surface protonation of the different crystallographic planes of kaolinite}

The surface acidity of simple and complex oxides is a consequence of the acid base characteristic of amphoteric surface hydroxyl groups. The protonation and deprotonation of surface $\mathrm{OH}$ groups are specified in terms of surface complexation equilibria (Schindler and Stumm, 1987). Different double-layer models were established to describe the experimentally observed pH-dependence of the acidity and stability constants of surface complexation reactions. The various models are equivalent in fitting the protonation reactions of $\delta-\mathrm{Al}_{2} \mathrm{O}_{3}$ (Westall and $\mathrm{Hohl}, 1980$ ). Based on the simple constant capacitance model the dependence of the dissociation constants on $\mathrm{pH}$ or charge is defined by:

$$
\begin{aligned}
& =\mathrm{MOH}_{2}^{+} \rightleftarrows=\mathrm{MOH}+\mathrm{H}^{+} \quad K_{a 1}^{s}=\frac{\{=\mathrm{MOH}\}\left[\mathrm{H}^{+}\right]}{\left\{=\mathrm{MOH}_{2}^{+}\right\}} \\
& =\mathrm{MOH} \rightleftarrows=\mathrm{MO}^{-}+\mathrm{H}^{+} \quad K_{a 2}^{s}=\frac{\left\{=\mathrm{MO}^{-}\right\}\left[\mathrm{H}^{+}\right]}{\{=\mathrm{MOH}\}} \\
& K_{a i}^{s}=K_{a i}^{s} \text { (int) } \exp \left(\frac{F \sigma}{C R T}\right) \quad(i=1,2)
\end{aligned}
$$

where $F, R$ and $T$ represent the Faraday constant, the molar gas constant and the temperature, respectively, $\sigma$ denotes the surface charge density $\left[\mathrm{mol} / \mathrm{m}^{2}\right]$ and is determined experimentally as a function of solution $\mathrm{pH}$ by acidimetric titration experiments. The two model parameters, the "intrinsic constant", $K_{a i}^{s}$ (int), and the integral capacitance of the flat double-layer, $C$, are computed from titration curves using the linear regression method as described by Schindler and Stumm (1987).

The main feature of clay minerals and micas is the layered crystallographic structure. The fundamental unit of the kaolinite structure, for example, is an extended sheet of two constituents: a silica-type layer of stoichiometric composition $\left(\mathrm{Si}_{4} \mathrm{O}_{10}\right)^{4-}$ and a gibbsite-type layer $(\mathrm{OH})_{6}-\mathrm{Al}_{4}-(\mathrm{OH})_{2} \mathrm{O}_{4}$ (schematic representation in Fig. 2a). Consequently, three morphological planes of different chemical compo- 


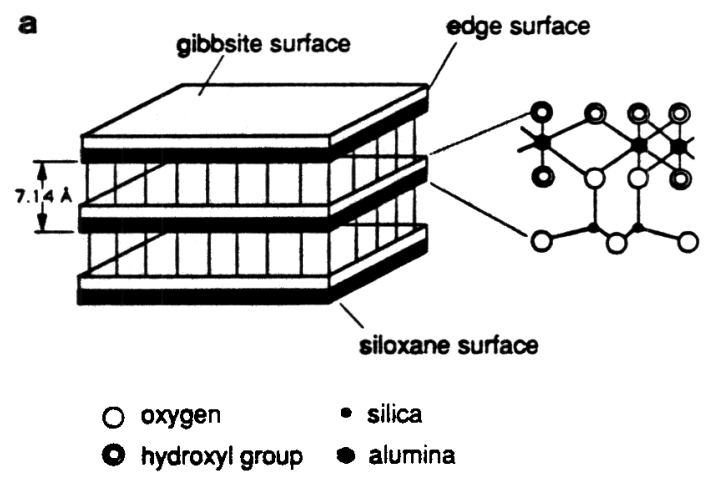

Figure 2 a. Schematic representation of the kaolinite structure. Left side: the stacking of successive layers; right side: the projected bonding scheme

b

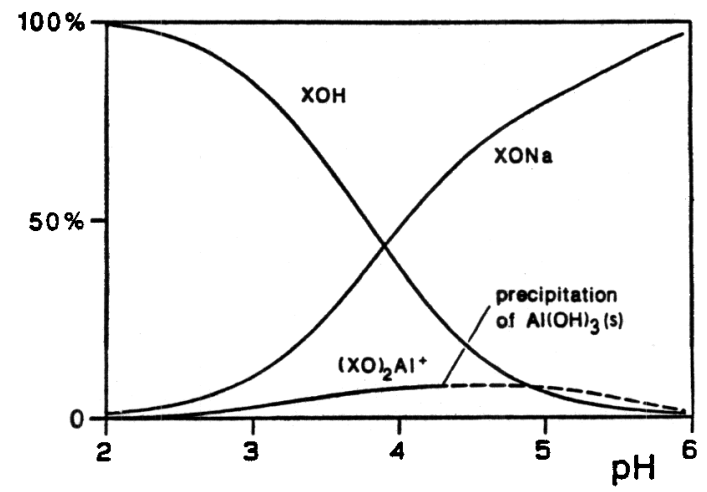

Figure $2 \mathrm{~b}$. Speciation of the siloxane surface as a function of $\mathrm{pH}$. Conditions: $I=0.1\left(\mathrm{NaNO}_{3}\right)$; $[\mathrm{Al}]_{\mathrm{t}}=1.610^{-4} \mathrm{M}$; Kaolinite: $35 \mathrm{~g} / 1 ;[\mathrm{XO}]_{1}=1.4610^{-3} \mathrm{M}$

sition exist at the kaolinite surface: a gibbsite layer and a siloxane layer (basal surfaces) and a complex oxide of the two constituents $\mathrm{Al}(\mathrm{OH})_{3}$ and $\mathrm{SiO}_{2}$ (edge surfaces) (Fig. 2a). Here we distinguish two types of surface ligands: (i) $=\mathrm{MOH}$ groups are involved in proton equilibria as defined in Eqs. 1-3. Different surface species belong to this ligand type such as $\mathrm{Al}-\mathrm{OH}-\mathrm{Al}$ groups at the gibbsite surface, $=\mathrm{AlOH}$ and $/$ or $=\mathrm{SiOH}$ groups at the edge surface and Si-O-Si groups at the siloxane layer. (ii) $\mathrm{XO}^{-}$groups react by ion exchange. They are probably induced by isomorphic substitution of $\mathrm{Si}$ by $\mathrm{Al}$ in the siloxane layer (Al-O-Si) ${ }^{-}$.

The charge distribution on kaolinite platelets can be shown by the formation of particle associations in kaolinite suspensions and electron microscopic studies (Thiessen, 1942; van Olphen, 1977). There is convincing evidence for a pH-dependent 


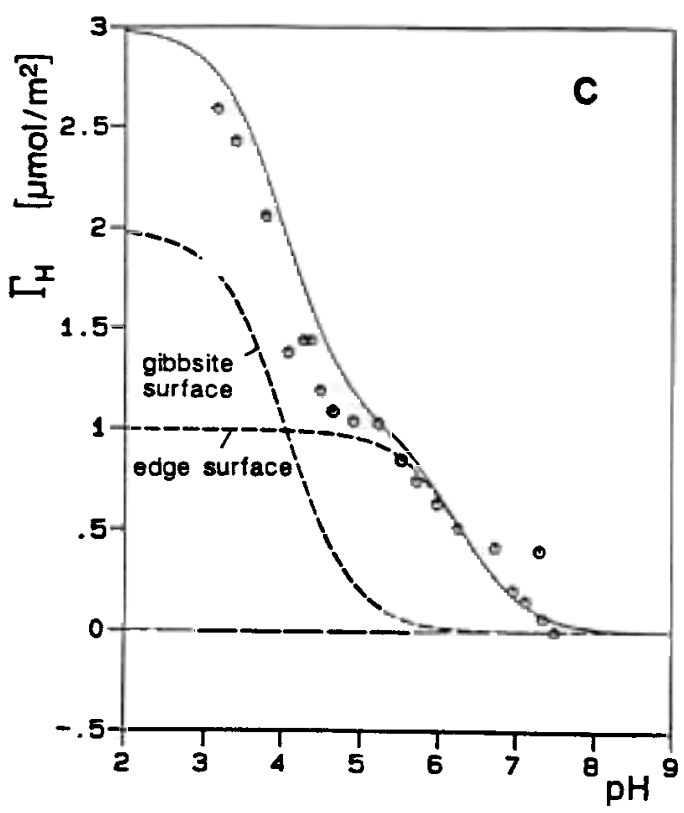

Figure 2c. Proton density $\Gamma_{H}$ at surface hydroxyl groups. Circles: experimental data; broken lines: successive protonation of two distinct types of hydroxyl groups at the gibbsite and edge surface; solid line: computed total proton density

charge at the edges of a kaolinite crystal (Thiessen, 1942). Van Olphen (1977) postulates a permanent negative charge localized at the siloxane layer. However, it is still a matter of controversy whether, in aqueous suspensions, the permanent charge of the basal surfaces are both negatively or even oppositely charged (Follett, 1965; Thompson and Hayward, 1987). Furthermore, the permanently negative charge can be a consequence of isomorphous substitution at the siloxane surface or caused by a contamination with very small amounts of 2:1 phyllosilicates ( $\mathrm{Lim}$ et al., 1980).

Our studies provide further evidence for the existence of permanent negatively charged surface sites $\mathrm{XO}^{-}$at the siloxane layer. The $\mathrm{XOH}$ groups at the siloxane layer are the main surface species at low $\mathrm{pH}$ and undergo ion exchange reactions with $\mathrm{Na}^{+}$and $\mathrm{Al}$ (III) (Fig. 2b). At $\mathrm{pH}<4.3, \mathrm{Al}^{3+}$ is the dominant $\mathrm{Al}$ (III) species and accessible to ion exchange reactions. In our studies, the solution is supersaturated with respect to $\mathrm{Al}(\mathrm{III})$ at $\mathrm{pH}>4.3$ and $\mathrm{Al}(\mathrm{OH})_{3}$ may precipitate. The ion exchange constants listed in Table 1 are either taken from Schindler et al. (1987) or experimentally determined by Wieland (1988).

The protonation of surface hydroxyl groups is displayed in Fig. 2c. The experimental methods of the acidimetric titrations are described by Wieland (1988). The model parameters, i.e. the intrinsic constants $K_{a i}^{s}$ (int) and the integral capacitance $C$ listed in Table 1, are based on the constant capacitance model. The surface proton concentration, $\Gamma_{H}$, denotes the proton density at $=\mathrm{MOH}$ groups with respect to the zero point of charge of the hydroxyl groups at the edge face $\left(\mathrm{pH}_{\mathrm{ZPC}}=7.5\right)$ (Ferris and 
Table 1. Surface parameters of a highly crystalline kaolinite (Cornish "China Clay")

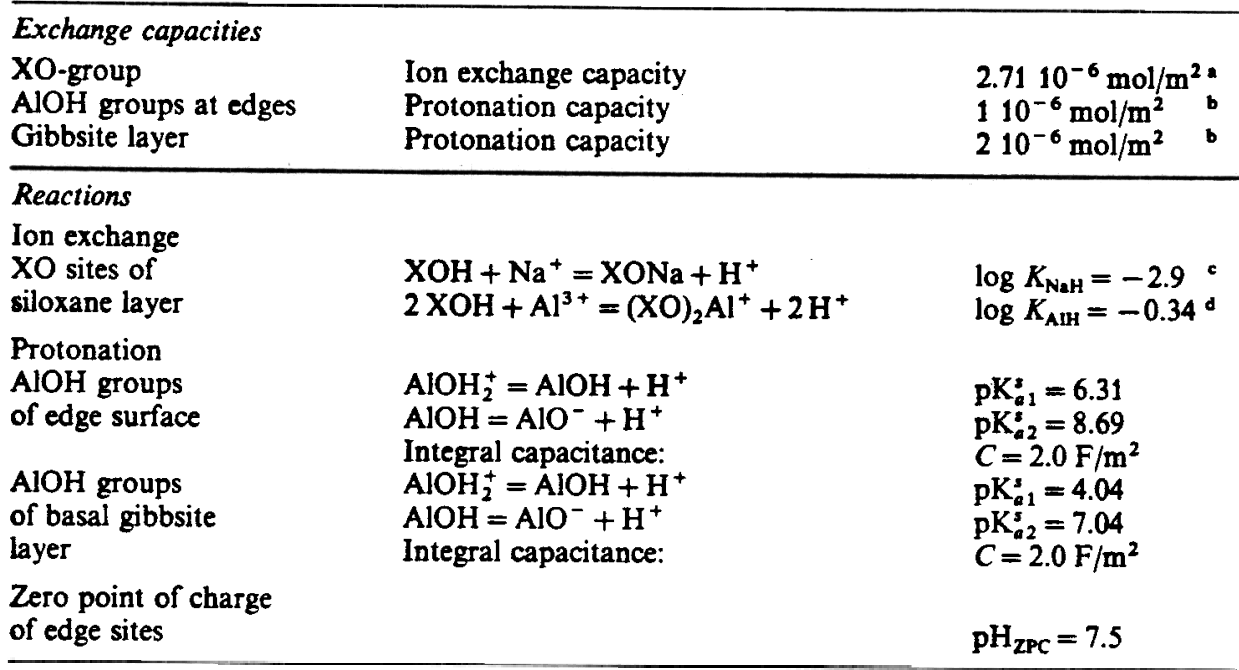

- Determination from acidimetric titrations at various electrolyte concentrations $(I=0.01-0.1 \mathrm{M})$

- Extrapolation in Fig. 2 b

- Schindler et al. (1987)

- Al desorption in kaolinite suspensions

- Determination from titration curves using the linear regression method (Schindler and Stumm, 1987)

Flegman et al. (1969), Ferris and Jepson (1975), Williams and Williams (1978)

- Estimated value

Jepson, 1975; Williams and Williams, 1978). At $\mathrm{pH}=7.5$, the proton density $\Gamma_{H}$ is zero and at $\mathrm{pH}<7.5$ it equals the surface charge, $\Gamma_{H}=\sigma$. The total proton density (solid line) is computed from the superposition of two successive protonation equilibria at the kaolinite surface (broken lines).

Surface hydroxyl groups are localized at the basal gibbsite layer and at the edge surfaces. The two branches of the titration curve given in Fig. $2 \mathrm{c}$ may be assigned to either one or both of these surfaces. If we assume that only hydroxyl groups at the edge surface are protonated, the maximum proton density at $\mathrm{pH} 2$ (Fig. $2 \mathrm{c}$ ) is about $9 \mathrm{H}^{+} / \mathrm{nm}^{2}$. Since the maximum proton density on surfaces of simple oxides ranges from 0.62 to $3 \mathrm{H}^{+} / \mathrm{nm}^{2}$, we assume that hydroxyl groups of both the edge and basal gibbsite surface are protonated. Hence we postulate that the edge surface is protonated in the near neutral and weakly acidic $\mathrm{pH}$ range, whereas the gibbsite surface is protonated at $\mathrm{pH}<5$ (Fig. $2 \mathrm{c}$ ). The intrinsic acidity constant of $=\mathrm{MOH}$ groups at the edge surface $\left(p K_{a 1}^{s}\right.$ (int) $=6.31 \pm 0.06 ; p K_{a 2}^{s}$ (int) $\left.=8.69\right)$ are comparable to the values determined for $\delta-\mathrm{Al}_{2} \mathrm{O}_{3}\left(p K_{a 1}^{s}\right.$ (int) $=7.4, p K_{a 2}^{s}$ (int) $=10$; (Kummert and Stumm, 1980). The intrinsic acidity constant $\mathrm{pK}_{a 1}^{s}$ (int) of the more acidic $=\mathrm{MOH}$ groups localized at the gibbsite surface is $4.04 \pm 0.18$ and, hence, they are significantly less acidic than $=\mathrm{SiOH}$-groups $\left(p K_{a 1}^{s}\right.$ (int) $<2, p K_{a 2}^{s}$ (int) $=6.56$; (Schindler and Stumm, 1987). The difference in acidity constants of Al-OH $\mathrm{OH}_{2}^{+}-\mathrm{Al}$ groups at 
the gibbsite layer and $=\mathrm{AlOH}_{2}^{+}$groups at the edge surface may reflect the different acidity constants of the corresponding dissolved species $\mathrm{Al}_{2}(\mathrm{OH})_{2}^{2+}$ and $\mathrm{Al}(\mathrm{OH})_{2}^{+}$. Thus we postulate that at $\mathrm{pH}<5.5$ the $\mathrm{Al}-\mathrm{OH}-\mathrm{Al}$ groups at the gibbsite surface and at $\mathrm{pH}<7.5$ the $=\mathrm{AlOH}$ groups at the edge surface, are protonated.

In summary, the proposed model of the acid-base characteristics of kaolinite platelets explains the $\mathrm{pH}$-dependent protonation of three distinct crystal surfaces: protonation and ion exchange equilibria at the basal siloxane layer (Fig. 2 b) and protonation of the hydroxyl groups at the basal gibbsite and the edge surface (Fig. 2c).

\section{Dissolution reactions on the kaolinite surface}

The rates of kaolinite dissolution were determined from the increase of $\mathrm{Al}$ and $\mathrm{Si}$ concentrations in solution which are linear with time and, hence, follow a zero order rate law (Wieland, 1988). Below $\mathrm{pH} \mathrm{7,} \mathrm{the} \mathrm{neutral} \mathrm{molecule} \mathrm{Si}(\mathrm{OH})_{4}$ is the major solute species of $\mathrm{Si}(\mathrm{IV})$. At low Si concentrations ([Si] $<10^{-4} \mathrm{M}$ ) and below $\mathrm{pH} 7$ adsorption of $\mathrm{Si}(\mathrm{OH})_{4}$ is not very important. On the other hand, $\mathrm{Al}^{3+}$ adsorbs on surfaces even at low pH (Fig. 2 b). Therefore dissolved $\mathrm{Si}$ is a better parameter for the determination of dissolution rates.

Dicarboxylic acids e.g. oxalate, malonate, salicylate and phthalate form five-, sixor seven-membered chelates with solute $\mathrm{Al}(\mathrm{III})$ as well as on the surface of $\delta-\mathrm{Al}_{2} \mathrm{O}_{3}$ (Furrer and Stumm, 1986). Oxalate and salicylate promote both $\mathrm{Al}$ and $\mathrm{Si}$ detachment from the kaolinite surface between $\mathrm{pH}$ 2-6 (Wieland, 1988). Since the dissolution of silica is not promoted in presence of these ligands (Bennett et al, 1988; Wieland, 1988), we conclude that the siloxan layer is not reactive with respect to dissolution processes and kaolinite dissolution is driven by the detachment of Al centers.

The pH dependence of kaolinite dissolution ( $R_{H, S i}$ in Fig. 3) may be explained by the protonation of the edges and the gibbsite surface (Fig. $2 \mathrm{c}$ ). In weakly acidic solutions the edge surface is protonated and, hence, proton promoted dissolution occurs at edges surface sites. At $\mathrm{pH}<5$, both the proton density and the dissolution rate, $R_{H, S i}$, of the edge surface remain constant. In this low $\mathrm{pH}$ range, $\mathrm{Al}-\mathrm{OH}-\mathrm{Al}$ groups at the gibbsite surface are protonated and dominate the overall weathering process of kaolinite.

The effect of solution $\mathrm{pH}$ on the dissolution rates of kaolinite, muscovite and their constituent oxides is summarized in Fig. 3. In the acid pH range, the dissolution of $\delta$ $\mathrm{Al}_{2} \mathrm{O}_{3}$ is promoted with increasing $\mathrm{H}^{+}$activity in solution, whereas the rate of silica dissolution (amorphous $\mathrm{SiO}_{2}$ and quartz) even decreases and remains constant at $\mathrm{pH}<3$. As a consequence of the low basicity of $=\mathrm{SiOH}$ groups, silica is uncharged in this $\mathrm{pH}$ range. In the near neutral and alkaline $\mathrm{pH}$ range the dissolution of silica is slightly increased. This indicates the important role of $\mathrm{H}_{2} \mathrm{O}$ and $\mathrm{OH}^{-}$as reactants at the silica water interface. The dissolution behavior of kaolinite and muscovite reveals the reactivity of $\mathrm{Al}$ centers at their surfaces. The $\mathrm{pH}$-dependence of muscovite dissolution is to be most likely a consequence of the protonation of the Al centers at the edge surface. 


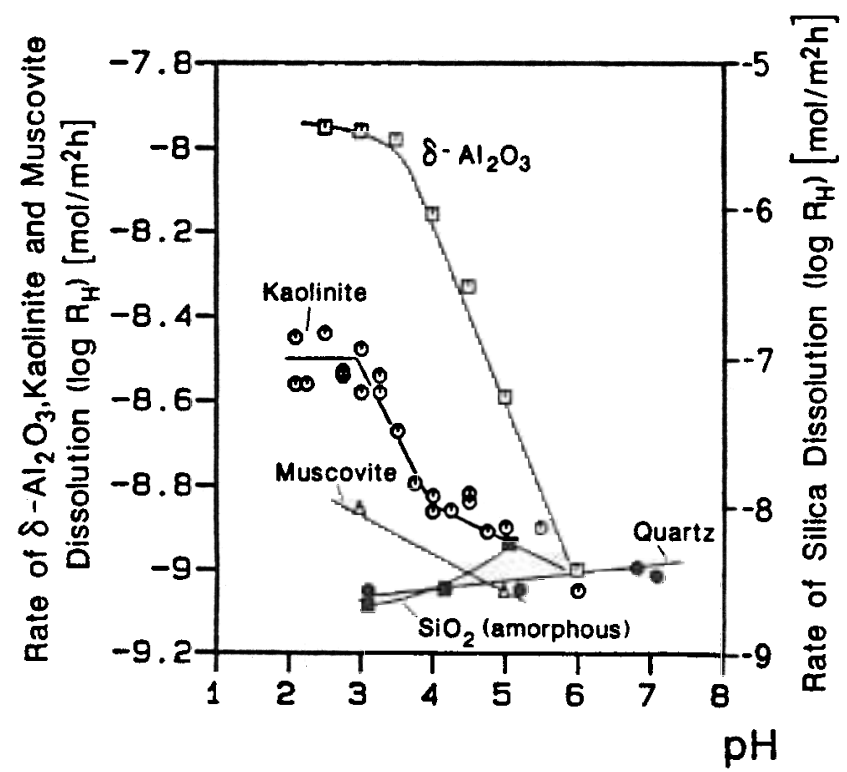

Figure 3. pH-dependent dissolution rates of the sheet silicates kaolinite and muscovite and their constituent oxides $\left(\delta-\mathrm{Al}_{2} \mathrm{O}_{3}\right.$ and amorphous $\mathrm{SiO}_{2}$ or quartz, respectively)

The blocking of active sites by cation adsorption

Several studies demonstrate that cations inhibit the dissolution process of minerals: $\mathrm{Al}(\mathrm{III})$ affects the dissolution of amorphous silica (Iler, 1973) and albite (Chou and Wollast, 1985) and $\mathrm{Mg}^{2+}$ and $\mathrm{Ca}^{2+}$ reduce the weathering rate of amorphous silica (Wirth and Gieskes, 1979) and calcite (Sjöberg, 1978), respectively.

Experimental study: the effect of vanadyl adsorption on the dissolution of $\delta-\mathrm{Al}_{2} \mathrm{O}_{3}$

The adsorption of $\mathrm{VO}^{2+}$ and its effect on the dissolution of $\delta-\mathrm{Al}_{2} \mathrm{O}_{3}$ is shown in Fig. 4. The S-shaped isotherm reveals two processes (Wersin et al., 1989): Specific adsorption of $\mathrm{VO}^{2+}$ at low concentrations $\left(\left[\mathrm{VO}^{2+}\right] \leqq 1 \mathrm{E}-7 \mathrm{~mol} / \mathrm{m}^{2}\right)$ and precipitation of the secondary phase ([VO $\left.{ }^{2+}\right] \geqq 1 \mathrm{E}-6 \mathrm{~mol} / \mathrm{m}^{2}$ ). Wehrli and Stumm (1989) found that $\mathrm{VO}^{2+}$ adsorbs specifically on $\delta-\mathrm{Al}_{2} \mathrm{O}_{3}$. The ${ }^{27} \mathrm{Al}$ ENDOR study by Motschi and Rudin (1984) provides compelling evidence for inner-sphere coordination of a bidentate $\mathrm{VO}^{2+}$ complex adsorbed on $\delta-\mathrm{Al}_{2} \mathrm{O}_{3}$. At pH $4.5,10 \%$ to $20 \%$ of total vanadyl are adsorbed on the positively charged surface $\left(\delta-\mathrm{Al}_{2} \mathrm{O}_{3}\right.$ : $\left.1.5 \mathrm{~g} / \mathrm{l} \approx 144 \mathrm{~m}^{2} / \mathrm{l}\right)$. At the maximum $\mathrm{VO}^{2+}$ coverage $\left(2.5 \mu \mathrm{mol} / \mathrm{m}^{2}\right)$ about $12 \%$ of the total $\mathrm{OH}$ groups $\left(\approx 21 \mu \mathrm{mol} / \mathrm{m}^{2}\right)$ act as surface ligands. Although $\mathrm{pH}$ was changed from $\mathrm{pH} 4.5$ to 3 at the beginning of each experiment, $\mathrm{VO}^{2+}$ coverage 


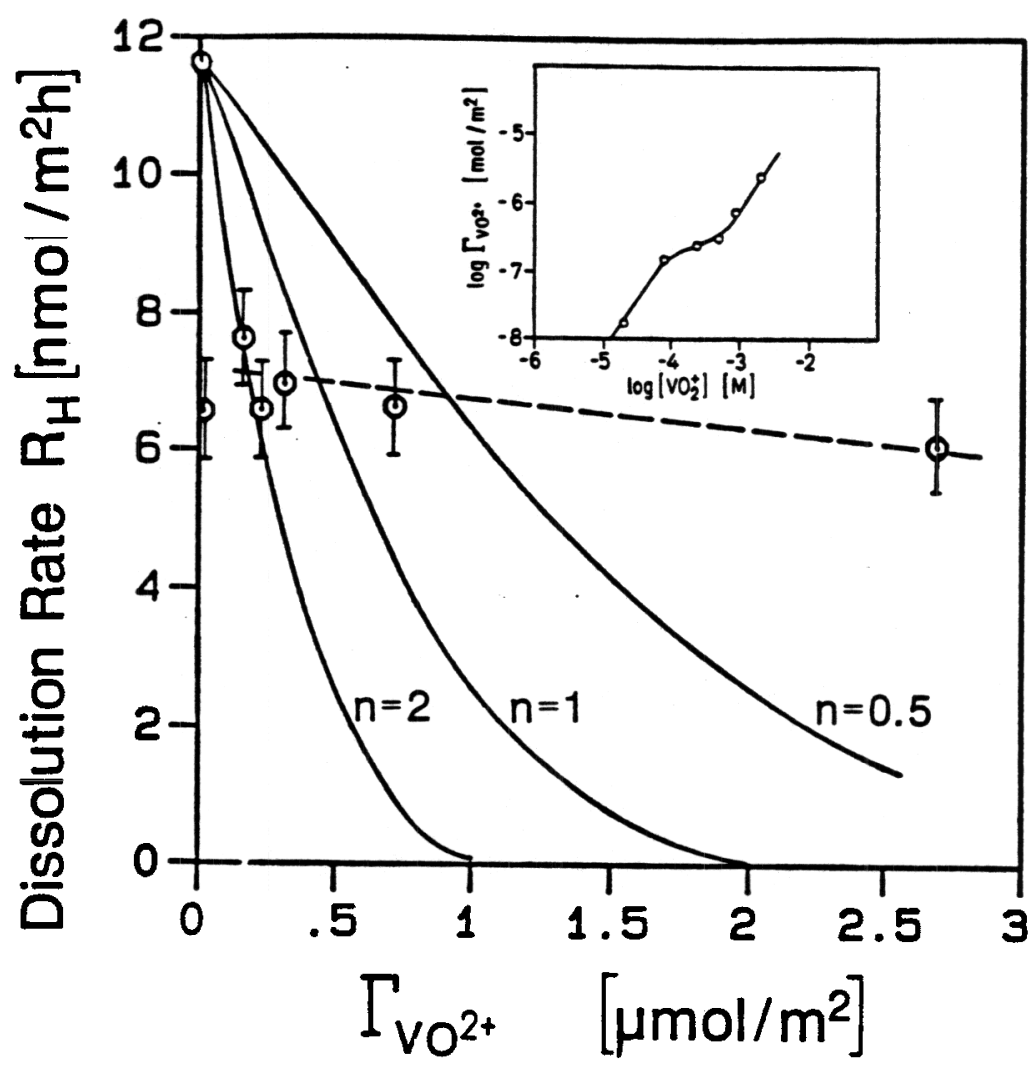

Figure 4. The dissolution rate of $\delta \cdot \mathrm{Al}_{2} \mathrm{O}_{3}$ in absence of vanadyl and at various concentrations of adsorbed vanadyl $\left(\delta-\mathrm{Al}_{2} \mathrm{O}_{3}: 1.5 \mathrm{~g} / \mathrm{l} ; I=0.1\left(\mathrm{NaNO}_{3}\right) ; \mathrm{pH}=3\right)$. $R_{H}$ is determined from a linear increase of $\mathrm{Al}$ in solution. The symbols represent experimental data. The solid lines are calculated from Eq. (7) for the indicated net proton-metal exchange coefficients $n$. The insert shows the adsorption isotherm ov vanadyl on $\delta-\mathrm{Al}_{2} \mathrm{O}_{3}$

$\left(\Gamma_{V o^{2+}}\right)$ remained constant during the dissolution reaction, most likely due to slow desorption kinetics.

As shown in Fig. 4, even low concentrations of $\mathrm{VO}^{2+}$ inhibit the protonpromoted dissolution. At $\Gamma_{V O^{2}+} \approx 1.710^{-8} \mathrm{~mol} / \mathrm{m}^{2}$ (corresponds to $0.08 \%$ of surface $\mathrm{OH}$ groups), the dissolution rate is reduced to about $60 \%$ of the dissolution rate in the absence of the cations. From this observation we may deduce an upper boundary for the mole fraction of active sites. The total concentration of Al-sites on aluminum oxides is $S_{t} \approx 1.610^{-5} \mathrm{~mol} \mathrm{~m}^{-2}$. From the lowest surface concentration $\left(\Gamma_{\mathrm{vo}^{2+}} \approx 1.710^{-8}\right)$ used we estimate the mole fraction of active sites, $x_{a}$, to be $\leqq 10^{-3}$. With increasing $\mathrm{VO}^{2+}$ coverage a secondary phase forms and, within the experimental error, the dissolution rate does not decrease significantly. Two hypotheses explain the fact that vanadyl adsorption reduces the dissolution rate only by $40 \%: 1$. Two different types of sites, such as dislocations and kinks, are active, but 
only one type is blocked by cation adsorption. 2. The desorption kinetics of $\mathrm{VO}^{2+}$ from the completely blocked sites controls the dissolution rate. In this case the half life of adsorbed vanadyl is almost twice as long as the half life of active sites.

\section{Theoretical approach: specific adsorption and precursor formation}

The term „dissolution-active center" refers to those surface metal centers which are localized on exposed surface positions such as kinks, steps, defect sites etc. They are usually denoted as the mole fraction of active sites, $x_{a}$. The inhibiting effect of adsorbed cations may principally be attributed to one of the following reactions occurring at the solid-liquid interface: i) cation-proton exchange reactions resulting in a decrease of the surface proton concentration and ii) blocking of dissolutionactive sites by specifically adsorbed cations.

The cation-proton exchange reaction of $\mathrm{VO}^{2+}$ with $\mathrm{H}^{+}$at the $\delta-\mathrm{Al}_{2} \mathrm{O}_{3}$ surface may

$$
n=\mathrm{MOH}_{2}^{+}+\mathrm{VO}^{2+} \rightarrow(=\mathrm{MOH})_{n} \mathrm{VO}^{2+}+n \mathrm{H}^{+}
$$

where $=\mathrm{MOH}_{2}^{+}$represents the proton concentration at the surface with respect to the zero point of charge, $(=\mathrm{MOH})_{n} \mathrm{VO}^{2+}$ denotes the $\mathrm{VO}^{2+}$ surface complexes. $\mathrm{VO}^{2+}$ and $\mathrm{H}^{+}$are the vanadyl and protons in solution, respectively. Eq. (4) accounts for the exchange of protons which may help forming precursor configurations. The (1986):
experimental rate law for the dissolution of $\delta-\mathrm{Al}_{2} \mathrm{O}_{3}$ is given by Furrer and Stumm

$$
R_{H}=k_{H} \Gamma_{H}^{3}\left[\mathrm{~mol} \mathrm{~m}^{-2} \mathrm{~h}^{-1}\right]
$$

$\Gamma_{H}$ denotes the surface proton concentration $\left[\mathrm{mol} / \mathrm{m}^{2}\right]$ and $k_{H}$ is an empirical rate constant $\left(k_{H}=310^{-9} \mathrm{~mol}^{-2} \mathrm{~m}^{4} \mathrm{~h}^{-1}\right)$. Cation adsorption may result in a reduction of the proton concentration expressed by the following equation

$$
\Gamma_{H}=\Gamma_{H}(0)-n \Gamma_{\mathrm{vo}^{2}+}\left[\mathrm{mol} \mathrm{m}^{-2}\right]
$$

where $\Gamma_{H}(0)$ stands for the proton concentration on the surface at $\mathrm{pH} 3$ in absence of adsorbing $\mathrm{VO}^{2+}\left(\Gamma_{H}(0)=2.48 \mu \mathrm{mol} / \mathrm{m}^{2}\right.$ in $\left.0.1 \mathrm{M} \mathrm{NaNO}_{3}\right)$ and $\Gamma_{\mathrm{VO}^{2+}}$ denotes the concentration of vanadyl surface complexes. The combination of Eq. (5) and (6)
yields

$$
R_{H}=k_{H}\left(\Gamma_{H}(0)-n \Gamma_{\mathrm{VO}^{2+}}\right)^{3}\left[\mathrm{~mol} \mathrm{~m}^{-2} \mathrm{~h}^{-1}\right]
$$

The net metal-proton exchange coefficient $n$ for $\mathrm{VO}^{2+}$ adsorbed on $\delta-\mathrm{Al}_{2} \mathrm{O}_{3}$ and $\mathrm{TiO}_{2}$ equals 2 (Wehrli and Stumm, 1989) indicating the formation of an inner-sphere coordinated, bidentate surface complex (Motschi and Rudin, 1984). The solid lines in Fig. 4 represent theoretical dissolution rates of $\delta-\mathrm{Al}_{2} \mathrm{O}_{3}$ calculated from Eq. (7) for $n=0.5,1$ and 2 and increasing $\mathrm{VO}^{2+}$ coverage. The calculations illustrate that the 
inhibiting effect of cations may not be attributed to a reduction of surface proton concentration. Even at high $\mathrm{VO}^{2+}$ coverage, cation adsorption and protonation are not competitive reactions at the surface.

We may now assume that active sites are blocked by cation adsorption, i.e. the inhibition of dissolution processes is a consequence of the reduction of the number of dissolution-active sites at the surface. Wieland et al. (1988) proposed a general rate law for the acid- and ligand-promoted dissolution of minerals. We now extend this rate law by considering the inhibiting effect of adsorbed cations. The rate expression is derived using probability arguments. Three factors affect the reactivity of a metal center at the solid-liquid interface:

1. Metal centers as active sites on the surface

The probability $w(A)$ of finding a metal center in a dissolution-active position (kinks, steps, dislocations) on the surface is given by:

$$
w(A)=x_{a}=\frac{S}{S_{t}}=\frac{s}{S_{t}}
$$

where $S$ and $S_{t}$ denote the density of active and total (=crystallographic) sites, respectively; $s$ and $s_{t}$ are the effective and the total surface area (Aagaard and Helgeson, 1982) and $x_{a}$ represents the mole fraction of active sites.

2. Formation of a precursor configuration at a metal center

A precursor configuration consists of a metal center surrounded by one or more protons. The formation of such a precursor is a prerequisite for the detachment of the metal center from the surface. The precursor configuration is activated in the ratedetermining step. The probability $w(J)$ of finding a metal center with four bridging $\mathrm{OH}$ groups in a position for activation with $j$ protons is given by Wieland et al. (1988)

$$
w(J)=x_{j}=\frac{4 !}{j !(4-j) !} x_{H}^{j}\left(1-x_{B}\right)^{4-j}
$$

where $x_{H}$ represents the mole fraction of protonated sites $\left(\Gamma_{H} / S_{t}\right)$ and $x_{j}$ is the mole fraction of a precursor configuration with $j$ nearest neighbor protons.

\section{Cation adsorption at a metal center}

The adsorption of cations is assumed to be a stochastic process, which leads to a random distribution of cations on the surface. The probability $w(M)$ for a metal center being coordinated to a specifically adsorbed cation is given by

$$
w(M)=x_{M}=\frac{\Gamma_{M}}{S_{t}}
$$

where $\Gamma_{M}$ is the cation density at the surface and $x_{M}$ represents the mole fraction of sites occupied by an adsorbed cation. The probability for a metal center not being coordinated to an adsorbed cation is $1-w(M)$. 
An individual metal center is considered dissolution reactive if all three conditions are met: (i) It is an active site, (ii) it is surrounded by $j$ protons and (iii) it is not coordinated to a specifically adsorbed cation. If the three events are statistically independent, the overall probability may be written as

$$
W=w(A) w(J)(1-w(M))
$$

Hence, the expression for the surface concentration $\Gamma_{P}$ of a suitable precursor configuration is

$$
\begin{aligned}
\Gamma_{P} & =S_{t} w(A) w(J)(1-w(M)) \quad\left[\mathrm{mol} \mathrm{m}^{-2}\right] \\
& =S_{t} x_{a} x_{j}\left(1-x_{M}\right)
\end{aligned}
$$
Finally, the general rate law of the elementary and rate-determining dissolution step
is

$$
R_{H}=k_{e} \Gamma_{P}=k_{e} S_{t} x_{a} x_{j}\left(1-x_{M}\right) \quad\left[\mathrm{mol} \mathrm{m}^{-2} \mathrm{~h}^{-1}\right]
$$

where $k_{e}$ denotes the rate constant of an elementary dissolution step. In the absence of adsorbed metal cations $\left(x_{M}=0\right)$, Eq. (13) may be simplified to the general rate law of the proton- and ligand-promoted dissolution of minerals (Wieland et al., 1988).

Using Eq. (13), the dissolution of albite at $\mathrm{pH} 3$ and various concentrations of dissolved $\mathrm{Al}^{3+}$ reported by Chou and Wollast (1985) may be reinterpreted. The experimental data of these authors are displayed in Fig. 5. Assuming a Langmuir type of isotherm for the Al adsorption on feldspar, $x_{\mathrm{Al}}$ may be expressed as

$$
x_{\mathrm{Al}}=x_{\mathrm{Al}, \max } \frac{[\mathrm{Al}]}{1 / K+[\mathrm{Al}]}
$$

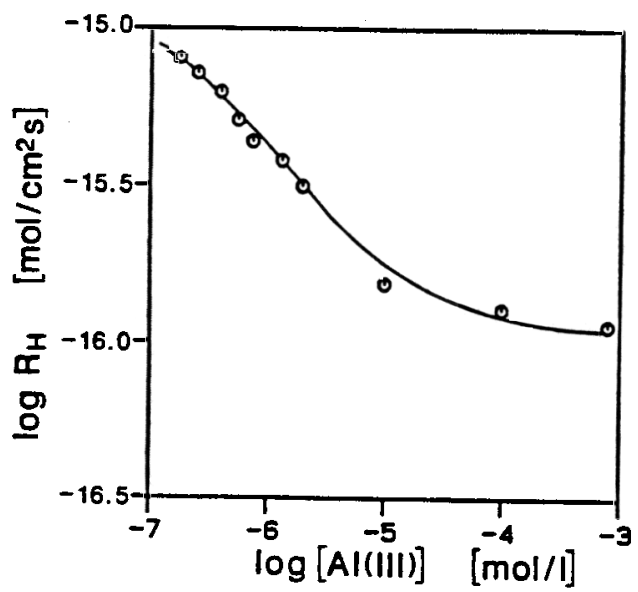

Figure 5. Dissolution of albite at $\mathrm{pH}$ 3. The logarithm of the apparent dissolution rate is plotted as a function $\log$ [Al], in solution. The circles represent experimental data from Chou and Wollast (1985). The curve was calculated with Eq. (13). For parameters see text 
The combination of Eq. (13) and (14) yields

$$
R_{H}=\log \left(k_{e} S_{t} x_{a} x_{j}\right)+\log \left(1-x_{\mathrm{Al}, \max } \frac{[\mathrm{Al}]}{1 / K+[\mathrm{Al}]}\right)
$$

$R_{B}$ in Fig. 5 (solid line) was calculated from Eq. (15) with $\log \left(k_{e} S_{z} x_{a} x_{j}\right)=-15.00$ and the fit-parameters $x_{\mathrm{Al}, \max }=0.88$ and $1 / K=510^{-7}$. The excellent agreement of Eq. (15) with the experimental data shows that the inhibition of albite dissolution may be explained by the blocking of dissolution-active sites. On the other hand the insert in Fig. 4 indicates that the adsorption of $\mathrm{VO}^{2+}$ at the $\delta-\mathrm{Al}_{2} \mathrm{O}_{3}$ surface may not be modelled by assuming a simple Langmuir isotherm. However, the failure of the proton displacement model (solid lines in Fig. 4) indicates that a specific blocking mechanism of active sites is also operative in this case. Cation inhibition experiments may therefore yield valuable insight into the surface concentration range of active sites.

\section{The estimation of active sites from exchange reactions in solution}

The formulation of surface chemical equilibria in terms of functional groups $=\mathrm{MOH}$, as reviewed Schindler and Stumm (1987), was very successful. Processes such as proton equilibria, cation adsorption and ligand exchange are formulated within the framework of a consistent thermodynamic model which accounts for only one out of four or six coordinated oxygen ligands of a surface center. However, if we consider dissolution reactions, all coordination sites on a surface metal center are potentially important. Therefore, we focus in this section on the symbol " $=$ " in the shorthand formula $=\mathrm{MOH}$. We will explore the potentials and limits of a structural viewpoint which considers the mineral-water interface as a two dimensional array of surface complexes. We will infer the coor-dinative structure of the surface sites from the crystallographic structure of Al-oxides and -hydroxides. Then we will compare the reactivity of different Al-phases with the decomposition rates of a structurally well defined species in solution. Our comparative kinetic discussion will focus in particular on the polynuclear complex $\left.\mathrm{Al}_{13} \mathrm{O}_{4}(\mathrm{OH})_{24}\left(\mathrm{H}_{2} \mathrm{O}\right)_{12}^{+}\right)^{+}$, the " $\mathrm{Al}_{13}$ " species.

\section{Structural constraints of active sites on mineral surfaces}

In a general way the coordination of a surface metal center can be formulated as:

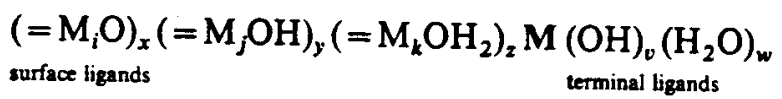

where the surface ligands connect the metal center with the bulk solid and the terminal ligands point towards the solution. The stoichiometric coefficients $v, w, x, y, z$ add to the coordination number of the metal center $M$. The indexes $i, j, k$ represent the number of nearest neighbor cations $M$ of the ligands $\mathrm{O}^{2-}, \mathrm{OH}^{-}$and $\mathrm{H}_{2} \mathrm{O}$ 
respectively. The formal charge $Z$ of the surface complex is determined from the relationship

$$
Z=Z_{M}-\frac{2 x}{i}-\frac{y}{j}-v
$$

The reactivity of a metal center is likely to increase with (i) the number of terminal ligands $(v+w)$ and (ii) the number of protons on the surface ligands $(y+2 z)$. In our context it is irrelevant how a specific configuration is formed. A large number of terminal ligands may arise from a stepped or spiral surface morphology, from screw dislocations or from point defects.

Coordination geometries of real Al-minerals are shown in Fig. 6. The 3D-graphs compare the surface site coordination of naturally occurring hydroxide minerals. The surface protons were distributed for zero net charge. A variety of tautomeric proton equilibria may produce other protonated or deprotonated species. The metal centers are distinguished according to the number of coordinated surface sites. Only three different site geometries occur on the $\mathrm{Al}(\mathrm{OH})_{3}$ surface with 6,4 and 2 surface ligands respectively (Fig. 6a). The complex 2 strongly resembles the surface complexes of adsorbed cations like $\mathrm{Cu}^{2+}$ or $\mathrm{VO}^{2+}$ (Motschi and Rudin, 1984).

The stoichiometries based on Eq. (16) are listed in Table 2. The assignment of detailed surface coordination and charge is more difficult with oxides and oxyhydroxides such as $\gamma$-AlOOH (boehmite, Fig. $6 \mathrm{~b}$ ). The number of possible configurations increases rapidly with the structural complexity of the mineral. Assuming zero total surface charge at $\gamma-\mathrm{AlOOH}$, for instance, it is impossible to formulate uncharged surface species. The formal charges $Z=-1 / 6$ on the boehmite step sites (5 surface ligands) exemplify that, on average, every sixth site will carry an additional proton in order to balance the overall charge of the mineral. Such additional protonated and deprotonated configurations are not included in Table 2 . However, within the kinetic framework of dissolution not all types of the different sites are equally important. Wehrli (1989) simulated the dissolution process of a simple cubic lattice with realistic kinetic parameters using the Monte Carlo technique. About $80 \%$ of the dissolution flux in this numerical model occurred at kink sites in which three out of six coordination sites are occupied by terminal ligands. Adsorbed species with only one or two surface ligands (such as the adatom and ledge sites in Fig. 1) dissolve very quickly, but they are present only in trace amounts. On the other hand, face sites such as the complexes 6 in Fig. $6 a+b$ are very abundant but react very slowly. The reactivities among different types of sites regulate the surface morphology in the steady state such that sites with equal or similar number of surface- and terminal ligands account for most of the reaction (Wehrli, 1989). If only one type of sites in Table 2 governs the dissolution kinetics it seems possible to use the reactivity of structurally well defined dissolved Al-centers as kinetic constraints for the structure of this precursor site.

\section{The model complex $\mathrm{Al}_{13}$}

The complex $\mathrm{Al}_{13} \mathrm{O}_{4}(\mathrm{OH})_{24}\left(\mathrm{H}_{2} \mathrm{O}\right)_{12}^{7+}$ is an ideal benchmark system for kinetic studies: It represents the smallest possible "oxide particle" consisting of a "bulk" of 
a)
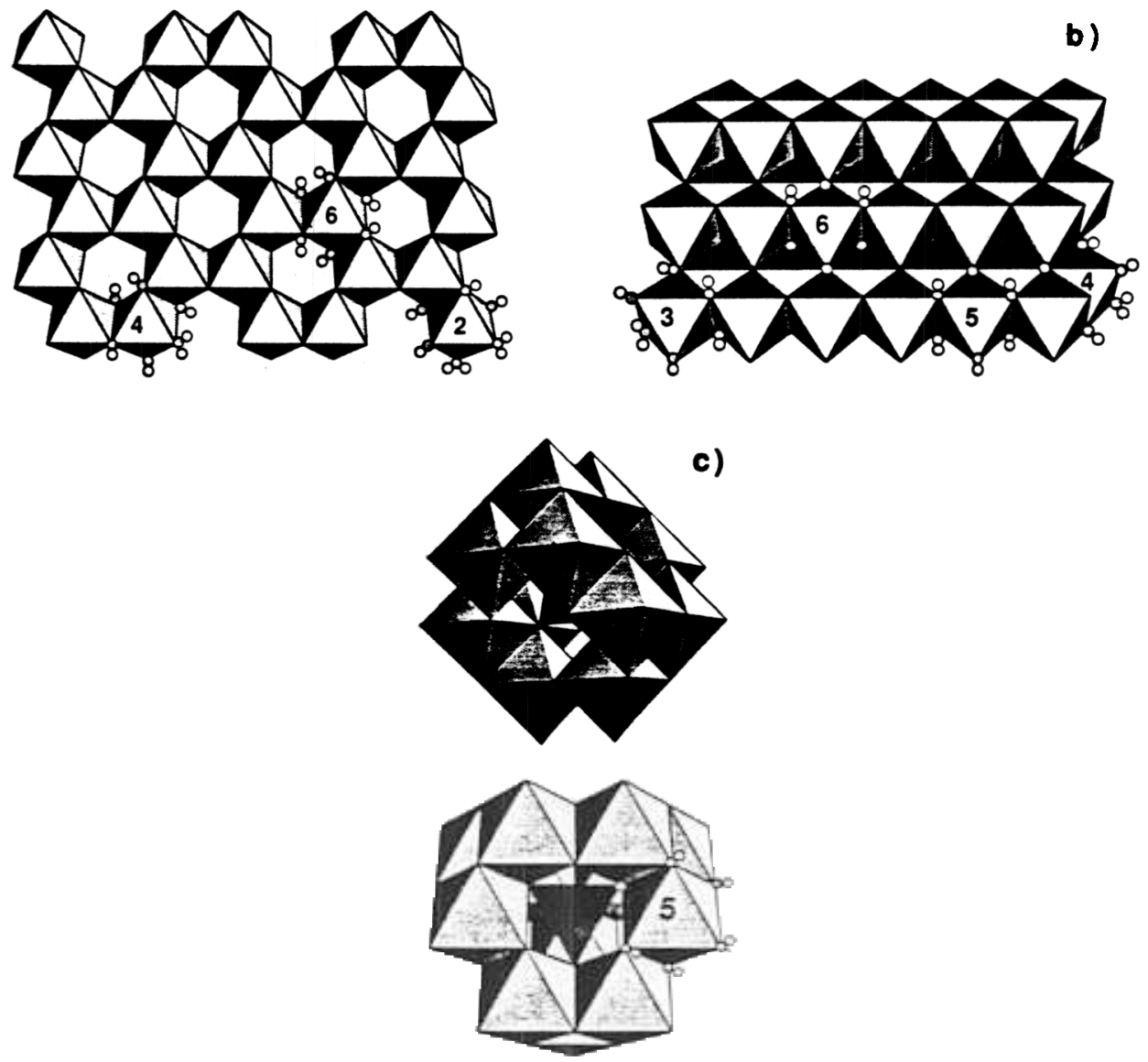

Figure 6. Structure of reactive sites (see Table 2 for stoichiometries). a) The three sites of gibbsite and bayerite, $\mathrm{Al}(\mathrm{OH})_{3}$. b) Surface sites of boehmite, $\gamma$-AlOOH. c) The structure of the $\mathrm{Al}_{13}$ polynuclear complex showing a tetrahedral center and 12 octahedral "surface" sites from two different perspectives. The open and filled circles represent hydrogen and oxygen, respectively. The number of surface ligands is indicated for the different types of sites

just one tetrahedral Al(III)-center and twelve octahedral "surface sites" with one terminal water molecule, one oxygen ligand and four bridging $\mathrm{OH}$ groups. The structure of the complex is shown in Fig. 6c. The structural comparison in Table 2 reveals that similar surface complexes are found at step sites in Al-oxyhadroxides. The use of different experimental methods has contributed to the identification of the "Keggin Structure" of $\mathrm{Al}_{13}$ : Potentiometric titrations of Baes and Mesmer (1976) indicated the formation of a highly polymeric species. The data support the assumption of $\mathrm{Al}_{2}(\mathrm{OH})_{2}^{4+}$ and $\mathrm{Al}_{13} \mathrm{O}_{4}(\mathrm{OH})_{24}\left(\mathrm{H}_{2} \mathrm{O}\right)_{12}^{7+}$ as the dominant polynuclear species. Johansson (1960) precipitated both complexes as sulfate salts and deter- 
Table 2. Typical coordination geometries of $\mathrm{Al}$ in surface complexes

\begin{tabular}{lll}
\hline Mineral $^{2}$ & Surface ligands & Surface complex \\
\hline $\mathrm{Al}_{13}$ & 5 & $\left(\mathrm{Al}_{4} \mathrm{O}\right)\left(\mathrm{Al}_{2} \mathrm{OH}\right)_{4} \mathrm{Al}_{\left(\mathrm{H}_{2} \mathrm{O}\right)^{+1 / 2}}$ \\
\hline & 6 & $\left(\mathrm{Al}_{2} \mathrm{OH}\right)_{6} \mathrm{Al}$ \\
& 4 & $\left(\mathrm{Al}_{2} \mathrm{OH}\right)_{4} \mathrm{Al}_{(\mathrm{OH})\left(\mathrm{H}_{2} \mathrm{O}\right)}$ \\
& 2 & $\left(\mathrm{Al}_{2} \mathrm{OH}\right)_{2} \mathbf{A l}(\mathrm{OH})_{2}\left(\mathrm{H}_{2} \mathrm{O}\right)_{2}$ \\
\hline Boehmite & 6 & $\left(\mathrm{Al}_{4} \mathrm{O}\right)_{4}\left(\mathrm{Al}_{2} \mathrm{OH}\right)_{2} \mathbf{A l}$ \\
$\gamma-\mathrm{AlOOH}$ & 5 & $\left(\mathrm{Al}_{4} \mathrm{O}\right)\left(\mathrm{Al}_{2} \mathrm{OH}\right)_{2}\left(\mathrm{Al}_{3} \mathrm{OH}\right)_{2} \mathbf{A l}(\mathrm{OH})^{-1 / 6}$ \\
& 4 & $\left(\mathrm{Al}_{4} \mathrm{O}\right)\left(\mathrm{Al}_{2} \mathrm{OH}\right)_{2}\left(\mathrm{Al}_{3} \mathrm{OH}\right)_{1} \mathbf{A l}(\mathrm{OH})\left(\mathrm{H}_{2} \mathrm{O}\right)^{+1 / 6}$ \\
& 3 & $\left(\mathrm{Al}_{2} \mathrm{OH}\right)\left(\mathrm{Al}_{3} \mathrm{OH}\right)_{2} \mathbf{A l}(\mathrm{OH})_{2}\left(\mathrm{H}_{2} \mathrm{O}\right)^{-1 / 6}$ \\
\hline
\end{tabular}

The structures are depicted in Fig. 4

- Compare Eqs. (16) and (17); surface ligands are indicated on the left hand side of the central Al(III) ion

mined their structure by X-ray diffraction. With the use of ${ }^{27} \mathrm{Al}$ NMR, Akitt et al. (1972) detected the tetrahedral Al-center of the $\mathrm{Al}_{13}$ complex in solution. The peak is shifted with respect to $\mathrm{Al}^{3+}(\mathrm{aq})$ by $-62.6 \mathrm{ppm}$. Bottero et al. (1980) and Bertsch et al. (1986) used the NMR technique to verify the speciation as postulated from potentiometric and wet chemical methods. While the structural coordination of the Al-centers in the polynuclear species is known in detail, the net charge of $\mathrm{Al}_{13}$ at different $\mathrm{pH}$ remains uncertain. Baes and Mesmer (1976) used the stoichiometry from Johansson (1960) with a +7 charge while Bottero et al. (1980) found that +3 fitted their titration data better. The question cannot be resolved with available data.

The complex $\mathrm{Al}_{13}$ is metastable with respect to $\mathrm{Al}^{3+}$ and crystalline gibbsite: We used the thermodynamic data from Baes and Mesmer (1976) and Stumm and Morgan (1981) and obtained a $\Delta G^{\circ}$ value of $-240 \mathrm{~kJ} / \mathrm{mol}$ for reaction (18) at $25^{\circ} \mathrm{C}$ and $I=0.01$ :

$$
3 \mathrm{Al}_{13} \mathrm{O}_{4}(\mathrm{OH})_{24}^{7+}+12 \mathrm{H}_{2} \mathrm{O} \rightarrow 7 \mathrm{Al}^{3+}+32 \mathrm{Al}(\mathrm{OH})_{3}(\mathrm{~s})
$$

Given the fact that $\mathrm{Al}_{13}$ forms rapidely in the laboratory from super saturated $\mathrm{Al}$ solutions the question arises if polymeric $\mathrm{Al}$ may be found in natural waters. The speciation diagram in Fig. 7 was calculated from the stability constants in Baes and Mesmer (1976). It shows that $\mathrm{Al}_{13}$ occurs down to concentrations of $[\mathrm{Al}]_{t}=50 \mu \mathrm{M}$. This value may easily be exceeded in acidified stream waters of catchments with granitic bedrock (Driscoll et al., 1984). The adsorption sites of the sediments in such rivers may already become Al-saturated at $20 \mu \mathrm{M}$ of total aluminum (Hall et al., 1985). The diagram in Fig. 7 predicts that in such a geochemical situation $\mathrm{Al}_{13}$ may be formed, if the river passes a carbonacious bedrock which neutralizes the river water.

\section{Decomposition kinetics of $\mathrm{Al}_{13}$}

The decomposition kinetics of $\mathrm{Al}_{13}$ was monitored indirectly with an automatic titrator in the $\mathrm{pH}$-stat mode. Because each solution was freshly synthesized the exact 


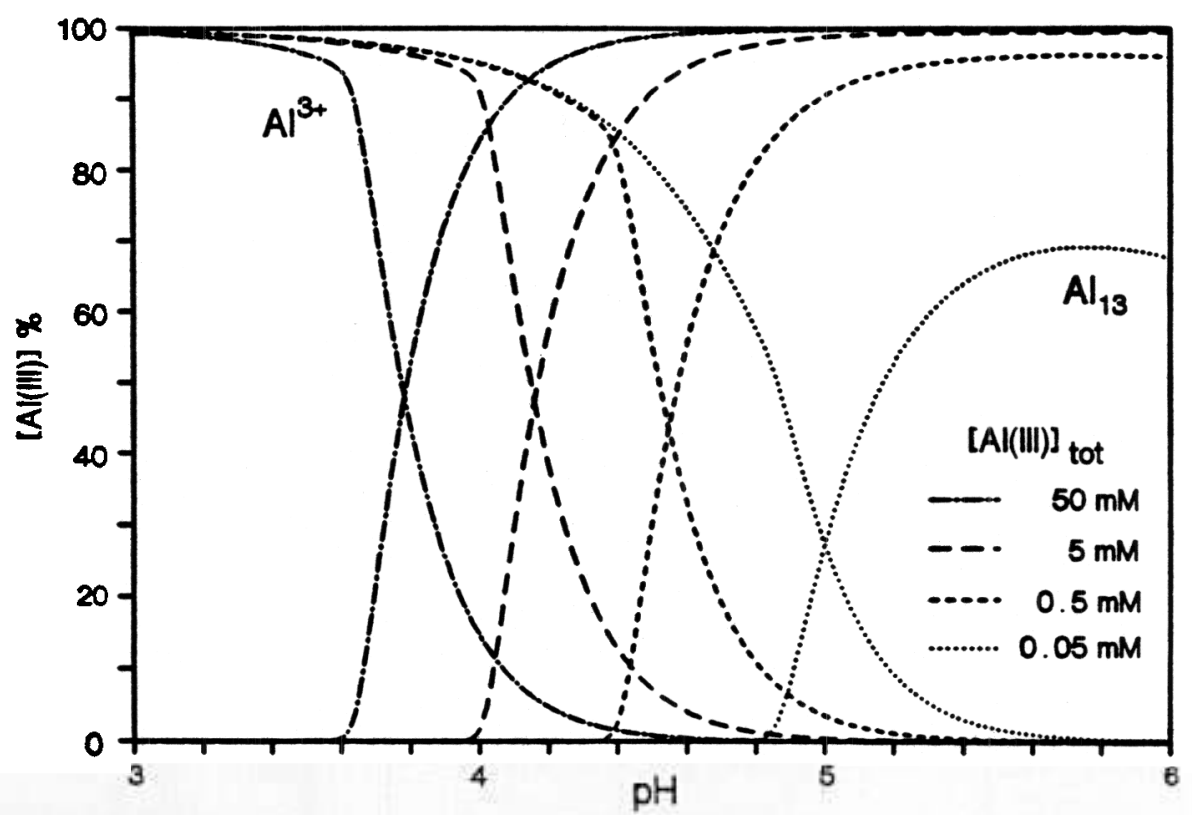

Figure 7. Speciation diagram of aqueous aluminum solutions in absence of a solid phase. The hydrolysis constants were taken from Baes and Mesmer (1976). Only $\mathrm{Al}^{3+}$ and the metastable $\mathrm{Al}_{13}$ complex are shown

concentration of $\mathrm{OH}^{-}$groups bound to $\mathrm{Al}^{3+}$ was known. Lowering the $\mathrm{pH}$ resulted in the decomposition of the polynuclear complex - a reaction which consumes $\mathrm{H}^{+}$:

$$
\mathrm{Al}_{13} \mathrm{O}_{4}(\mathrm{OH})_{24}\left(\mathrm{H}_{2} \mathrm{O}\right)_{12}^{7+}+32 \mathrm{H}^{+} \rightarrow 13 \mathrm{Al}^{3+}+40 \mathrm{H}_{2} \mathrm{O}
$$

In order to keep the $\mathrm{pH}$ constant the automatic burette replaced the consumed protons by adding $\mathrm{HCl}$ solution. Thus the disappearance of bound hydroxide, $\left[\mathrm{OH}^{-}\right]_{b}$, could be analyzed as a function of time. The initial $\mathrm{pH}$-adjustment occurred at the maximum speed of the burette. Therefore all experiments in Fig. 8 initially follow the same curve. Because the equilibrium concentration of the mono- and dimeric aluminum-hydroxo complexes at the experimental $\mathrm{pH}$ may vary, the observed first order plots yield different extrapolated initial concentrations. The curves were analyzed for times greater than 20 minutes. A first order reaction was observed following the empirical rate law:

$$
-\frac{13}{32} \frac{\mathrm{d}\left[\mathrm{Al}_{13}\right]}{\mathrm{d} t}=-\frac{\mathrm{d}\left[\mathrm{OH}^{-}\right]_{b}}{\mathrm{~d} t}=k\left[\mathrm{OH}^{-}\right]_{b}
$$

Typical first-order plots are shown in Fig. 8. Both kinetic series with total aluminum concentrations $[\mathrm{A}]$, of 5 and $50 \mathrm{mM}$ yielded identical results, which confirms the firstorder rate law in Eq. (20). Because the exact charge of $\mathrm{Al}_{13}$ is not known so far, the 


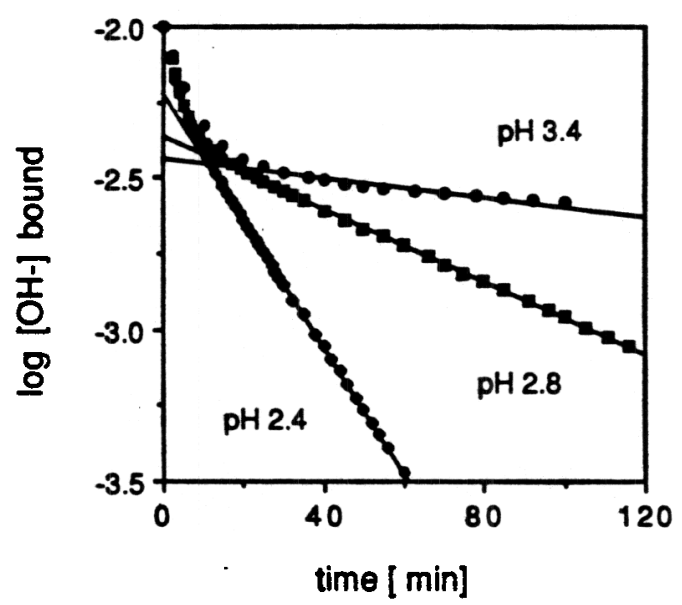

Figure 8. Typical first-order plots of the $\mathrm{Al}_{13}$ decomposition kinetics. Conditions: $[\mathrm{Al}]_{t}=5 \mathrm{mM}$; initial $[\mathrm{NaOH}]_{t}=10 \mathrm{mM} ;[\mathrm{NaCl}]=1 \mathrm{M} ; 25^{\circ} \mathrm{C}$

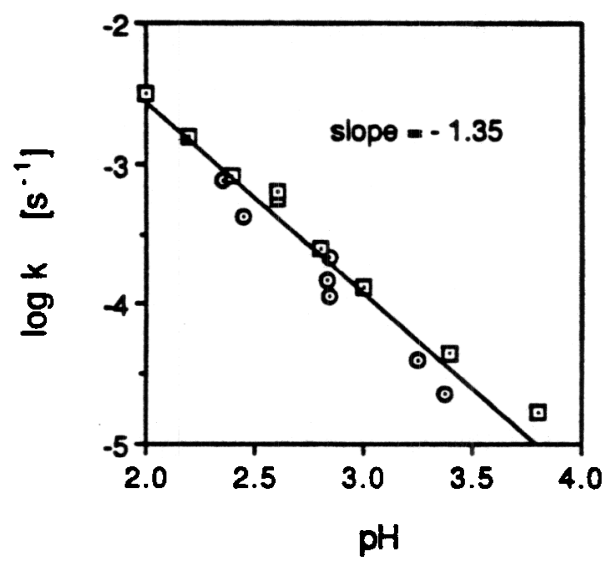

Figure 9. $\mathrm{pH}$ dependence of the $\mathrm{Al}_{13}$ decomposition rate. Conditions: $[\mathrm{NaCl}]=1 \mathrm{M} ;[\mathrm{OH}]_{\ell} /[\mathrm{Al}]_{\ell}$ $=2.0 ; 25^{\circ} \mathrm{C}$. Squares: $\mathrm{Al}_{t}=5 \mathrm{mM} ;$ dots: $[\mathrm{Al}]_{t}=50 \mathrm{mM}$

stoichiometric factor may be different from $13 / 32$. Therefore the absolute rate $\mathrm{d}\left[\mathrm{Al}_{13}\right] / \mathrm{d} t$ cannot be determined. The first-order rate constant $k$, however, is valid for both parameters $\left[\mathrm{Al}_{13}\right]$ and $\left[\mathrm{OH}^{-}\right]_{b}$. Figure 8 indicates that an increasing proton concentration accelerates the decomposition rate. The corresponding $\mathrm{pH}$ dependence of the reaction rate is shown in Fig. 9. From the slope of the plot $\log k v s$. $\mathrm{pH}$ we deduce the empirical rate law:

$$
-\frac{13}{32} \frac{\mathrm{d}\left[\mathrm{Al}_{13}\right]}{\mathrm{d} t}=-\frac{\mathrm{d}\left[\mathrm{OH}^{-}\right]_{b}}{\mathrm{~d} t}=k^{\prime}\left[\mathrm{OH}^{-}\right]_{b}\left[\mathrm{H}^{+}\right]^{1.35}
$$


with $k^{\prime}=1.31 \mathrm{M}^{-1.35} \mathrm{~s}^{-1}$. Hem (1983) found a similar behavior of aged aluminum hydroxide solutions. He observed a fractional $\mathrm{pH}$ dependence of the order of 1.7. His rate constants were lower by a factor of 10 and the data scattered considerably. We suspect that Hem's solutions contained micro-crystalline solids, which explains in part the slower decomposition kinetics and the variations in the data set. Since unpublished data of Schindler (personal communication) support our rate law (Eq. 21) we are confident that the observed reaction corresponds to the decomposition of pure $\mathrm{Al}_{13}$. The fractional $\mathrm{H}^{+}$dependence may indicate the participation of "surface" protons or the occurrence of two parallel decomposition processes. The detailed proton equilibria of $\mathrm{Al}_{13}$ are required, however, to validate a mechanistic interpretation. Here we confine ourselves to a comparison of the $\mathrm{Al}_{13}$ reactivity with substitution kinetics at the $\mathrm{Al}$ (III)-ion in solution and dissolution reactions of solids.

\section{Other homogeneous exchange processes}

The decomposition rates of $\mathrm{Al}_{13}$ is compared in Table 3 with other exchange processes at the $\mathrm{Al}$ (III) center. Where necessary bimolecular rate constants have been converted to pseudo-first-order constants for $\mathrm{pH}=3$. Three types of reactions are relevant in this context: Proton transfer, water exchange and decomposition of polynuclear hydroxo complexes. Proton transfer reactions in solution occurs extremely fast. Holmes et al. (1968) determined protonation kinetics of the reaction

$$
\mathrm{Al}(\mathrm{OH})^{2+}+\mathrm{H}^{+} \stackrel{k}{\rightarrow} \mathrm{Al}^{3+} \mathrm{aq}
$$

with a second-order rate constant $k=4.410^{9} \mathrm{M}^{-1} \mathrm{~s}^{-1}$. In Table 3 we list the corresponding pseudo-first-order rate constant at $\mathrm{pH}=3, k=4.410^{6} \mathrm{~s}^{-1}$. Based on a NMR study Akitt et al. (1972) estimated that the proton exchange rate at the $\mathrm{Al}_{13}$ center is in the same order of magnitude. Pressure jump experiments (Yasunaga and Ikeda, 1986) established that the protonation kinetics at oxide interfaces are several orders of magnitude slower: The intrinsic protonation constant for hematite at $\mathrm{pH} 3$ is $k_{\text {int }}=240 \mathrm{~s}^{-1}$. Compared to the slow dissolution kinetics of minerals, however, we may still treat the proton reactions as equilibria.

Aluminum is a moderately inert metal center with respect to water exchange (Hunt and Friedman, 1983). The homogeneous water exchange rate of $0.17 \mathrm{~s}^{-1}$ is

Table 3. Homogeneous processes at the Al(III) center *

\begin{tabular}{|c|c|c|}
\hline Process & $k\left[s^{-1}\right]$ & Reference \\
\hline $\begin{array}{l}\text { Protonation of } \mathrm{Al}(\mathrm{OH})^{2+} \\
\text { Proton exchange at } \mathrm{Al}_{13} \\
\text { Water exchange at } \mathrm{Al}^{3+} \\
\text { Decomposition of dimer } \\
\text { Decomposition of } \mathrm{Al}_{13}\end{array}$ & & $\begin{array}{l}\text { Holmes et al. (1968) } \\
\text { Akitt et al. (1972) } \\
\text { Hunt and Friedman (1983) } \\
\text { Akitt et al. (1972) } \\
\text { This work }\end{array}$ \\
\hline
\end{tabular}

\footnotetext{
Conditions: $25^{\circ} \mathrm{C}$ and $\mathrm{pH} \sim 3$
} 
slow compared to very labile aqueous ions like $\mathrm{Cu}^{2+}\left(>10^{8} \mathrm{~s}^{-1}\right)$ but fast compared to very inert centers like $\mathrm{Cr}^{3+}\left(5.810^{-7} \mathrm{~s}^{-1}\right)$. Coordinated $\mathrm{OH}^{-}$accelerates the substitution of water by a factor of 600 , which has also been observed for $\mathrm{Fe}^{3+}$.

Two pathways are important in the decomposition of binuclear complexes with bridging $\mathrm{OH}^{-}$groups: Spontaneous decay and an acid catalyzed reaction (Lutz and Wendt, 1970).

$$
\begin{aligned}
\mathrm{M}_{\mathrm{OH}}^{\mathrm{OH}} \mathrm{M} & \rightarrow 2 \mathrm{MOH} \\
\uparrow \downarrow \mathrm{H}^{+} & \\
\mathrm{M}_{\mathrm{OH}}^{\mathrm{HOH}} \mathrm{M} & \rightarrow \mathrm{M}+\mathrm{MOH}
\end{aligned}
$$

The authors determined the decomposition kinetics of the ferric and the vanadyl dinuclear complexes, $\mathrm{Fe}_{2}(\mathrm{OH})_{2}^{4+}$ and $(\mathrm{VO})_{2}(\mathrm{OH})_{2}^{2+}$ respectively. They observed the following rate law:

$$
R=\left(k_{1}+k_{2}\left[\mathrm{H}^{+}\right]\right)\left[\mathrm{M}_{2}(\mathrm{OH})_{2}\right]
$$

with corresponding rate constants of $k_{1}=0.8$ and $17 \mathrm{~s}^{-1}$ and $k_{2}=1.2$ and $205 \mathrm{M}^{-1} \mathrm{~s}^{-1}$ for the decomposition the Fe(III) and the V(VI) species, respectively. At $\mathrm{pH}=3$ the direct decomposition dominates the reaction. Both first-order constants $k_{1}$ are close to the decay constant for $\mathrm{Al}_{2}(\mathrm{OH})_{2}^{4+}$ of $k_{1} \sim 1 \mathrm{~s}^{-1}$ which was estimated by Akitt et al. (1972) from NMR data. Compared to this approximated value for the Al-dimer decomposition the reaction of $\mathrm{Al}_{13}$ at $\mathrm{pH} 3$ proceeds slower by a factor of $10^{4}$. Thus the more rigid coordination within a quasi-spherical geometry and the internal linkage with on $\mathrm{O}^{2-}$ ligand produces a coordinative environment which is considerably more inert than two simple $\mathrm{OH}^{-}$bridges.

\section{Kinetic constraints for the mole fraction of active $\mathrm{Al}$ (III)-sites}

Because active surface sites are regenerated in dissolution experiments usually zerothorder kinetics is observed with $R_{H}=k_{H}$. In comparing these surface rate constants with the reactivity of dissolved species we face two problems: i) Because surface protons enter the mechanistic rate law we should compare oxides at conditions of equal surface charge. ii) All homogeneous reactivities in Table 3 are given as (pseudo) first-order rate constants. Therefore we should convert experimental zeroth order rate constants of dissolution reactions to first order.

The first requirement is approximated easily. The Al-(hydr)oxides all exhibit quite similar $\mathrm{pH}_{\mathrm{ZPC}}$ values. Wieland et al. (1988) showed that under these conditions the surface charge of different solid phases will be quite similar for a given $\mathrm{pH}$. Assuming a charge of +7 of $\mathrm{Al}_{13}$ (Baes and Mesmer, 1976) and a radius of $0.54 \mathrm{~nm}$ (Johansson, 1960) we calculate a "surface charge" of $1.92 \mathrm{H}^{+} \mathrm{nm}^{-2}$ for the quasispherical $\mathrm{Al}_{13}$. For oxides Wieland et al. (1988) reported typical maximum protonation densities of $2 \mu$ moles $\mathrm{m}^{-2}$ or $1.2 \mathrm{H}^{+} \mathrm{nm}^{-2}$. Thus, the oxides reach at $\mathrm{pH} \sim 3$ a similar surface charge as the $\mathrm{Al}_{13}$ species. 
In order to derive a first order rate constant from experimental dissolution rates, we may use the total concentration of surface sites $S_{t}$

$$
R_{H}=k_{m} S_{s}
$$

where $k_{m}\left[\mathrm{~s}^{-1}\right]$ represents the mean reactivity of all surface sites. The density of sites at Al-mineral surfaces may be derived as follows: Wells (1975) lists a Al-OH distance of $1.98 \AA$ for diaspore $(\alpha-\mathrm{AlOOH})$. The corresponding $\mathrm{Al}-\mathrm{Al}$ distance in a hydrous mineral surface is $2.8 \AA$. This value translates to an Al-density of 9.82 sites nm $^{-2}$ in a hexagonal surface layer such as those in Fig. 6a. The corresponding surface concentration is $S_{t}=1.6410^{-5}$ moles $\mathrm{m}^{-2}$. We use this value in Eq. (25) to calculate the first order rate constants $k_{m}$ in Table 4 . It is remarkable that the half life of a surface site spans a range of more than a year (corundum) to less than a day (bayerite). The thermodynamically more stable corundum reacts slower than the more soluble bayerite. The faster dissolution rate of $\delta-\mathrm{Al}_{2} \mathrm{O}_{3}$ compared to corundum is to be expected since this spinell-type solid contains randomly distributed tetrahedral sites. These sites are coordinatively unsaturated and may bind water expanding their coordination number and creating point defects. Bayerite dissolves fastest because of its layered two-dimensional structure and the absence of strong $\mathrm{O}^{2-}$ surface ligands. Silica layers in kaolinite and muscovite inhibit the reactivity of the gibbsite-layers by a two orders of magnitude. The half life of our model compound for kink or step sites, the $\mathrm{Al}_{13}$ species, at $\mathrm{pH}=3$ is about 1.5 hours. Under this condition aluminum centers in $\mathrm{Al}_{13}$ react about 10 times faster than average $\mathrm{Al}$ surface complexes in Bayerite and about 10000 times faster than sites at the corundum-water interface.

The general rate law for mineral dissolution (Eq. 13) may help us to calculate the mole fraction of precursor complexes, $x_{P}$, as

$$
x_{P}=\frac{R^{H}}{k_{e} S_{t}}
$$

Table 4. Dissolution of $\mathrm{Al}$ minerals and $\mathrm{Al}_{13}$ *

\begin{tabular}{lllll}
\hline Mineral & $\begin{array}{l}\text { Rate } R_{H} \\
{\left[\mathrm{~mol} \mathrm{~m}^{-2} \mathrm{~s}^{-1}\right]}\end{array}$ & $\begin{array}{l}k^{\mathrm{b}} \\
{\left[\mathrm{s}^{-1}\right]}\end{array}$ & $\begin{array}{l}t_{1 / 2} \\
\text { [days] }\end{array}$ & Ref. \\
\hline Corundum & $2.010^{-13}$ & & & \\
Muscovite & $3.910^{-13}$ & & 2 \\
Kaolinite & $8.310^{-13}$ & & 3 \\
$\delta$ - $\mathrm{Al}_{2} \mathrm{O}_{3}$ & $3.010^{-12}$ & & 4 \\
Bayerite & $1.510^{-10}$ & & This work \\
$\mathrm{Al}_{13}$ & & & \\
\hline
\end{tabular}

- $\mathrm{pH}=3$ and $25^{\circ} \mathrm{C}$

- Calculated from Eq. (25) with $S_{t}=1.410^{-3} \mathrm{~mol} \mathrm{~m}^{-2}$ for Muscovite and Kaolinite (Wieland, 1988) and $S_{t}=1.6410^{-5}$ for the other minerals

- References: 1) Carroll-Webb and Walther (1988), 2) Wieland (1988), 3) Furrer and Stumm (1986), 4) Pulfer et al. (1984) 
Here we have used the definition $x_{P}=\Gamma_{P} / S_{t} . R_{H}$ is obtained from experiments (see Table 4) and $S_{t}=1.6410^{-5}$ moles $\mathrm{m}^{-2}$ as derived above. The microscopic rate constant $k_{\mathrm{e}}$ for the reactivity of the precursor complex is unknown. If we assume that Al-centers in a similar coordinative environment dissolve with similar kinetics we may use homogeneous rate constants of structurally defined complexes as estimates for $k_{e}$. Based on this assumption we insert the rate constants for the decomposition of the polynuclear species $\mathrm{Al}_{2}(\mathrm{OH})_{2}^{2+}$ and $\mathrm{Al}_{13}$ from Table 3 into Eq. (26) and obtain estimates $x_{p}$ (est.) for the mole fractions of precursor sites with the same coordination geometries as the dinuclear complex and $\mathrm{Al}_{13}$.

For bayerite the splitting of two OH-bridges in the dimer $\mathrm{Al}_{2}(\mathrm{OH})_{2}^{4+}$ models quite closely the dissolution of site 2 in Fig. 6 a. For geometric reasons the ratelimiting step is the detachment of site 4 , which should react slower. Thus in Table 5 the value of $x_{p}($ est. $)=9.210^{-6}$ at bayerite calculated from the dimer decomposition represents a lower boundary for the mole fraction of the active sites of type $4\left(x_{p} \geqq 9.210^{-6}\right)$. The lack of a coordinated $\mathrm{O}^{2-}$ ligand on bayerite sites should result in higher $k_{e}$ values of site 4 compared to the rate constant for $\mathrm{Al}_{13}$ decomposition. If we use the reactivity of $\mathrm{Al}_{13}$ as a kinetic bench mark, we calculate form Eq. (26) a value $x_{p}$ (est.) $=0.076$. This represents an upper boundary for the mole fraction of precursor sites 4 at the bayerite surface. In conclusion we obtain the following kinetic constraint on $x_{P}$ for bayerite: $9.210^{-6} \leqq x_{P} \leqq 0.076$.

A comparison between the structure of $\mathrm{Al}_{13}$ and $\gamma-\mathrm{AlOOH}$ in Fig. 6 reveals that the coordination of the polynuclear is similar to the structure of step sites at the oxyhydroxide. Monte Carlo simulations (Wehrli, 1989) predict that the kink sites 3 in Fig. $6 \mathrm{~b}$ account for most of the dissolution flux at such minerals. The kinks are expected to react faster than the step sites. Thus the reactivity of $\mathrm{Al}_{13}$ yields estimates for mole fractions of precursors in step configurations. Kinks will be present in lower concentrations. Therefore the estimates of $x_{P}$ (est.) $=1.010^{-4}$ at corundum and $x_{p}($ est. $)=1.510^{-3}$ at $\delta-\mathrm{Al}_{2} \mathrm{O}_{3}$ in Table 5 represent upper boundaries for the mole fraction of kink precursors at these minerals. Notice that the estimate $x_{P} \leqq 1.510^{-3}$ for $\delta-\mathrm{Al}_{2} \mathrm{O}_{3}$ is compatible with the experimental boundary of $x_{P} \leqq 10^{-3}$ reported in the previous section. These estimates have important implications. If we consider to determine the kinetically reactive surface structures by spectroscopic methods we face a dramatic sensitivity problem: Not only should the technique discriminate the predominant bulk sites with respect to the surface sites, but it has to be sensitive for kink sites in the probable concentration range $x_{P} \leqq 10^{-3}$.

Table 5. Estimated mole fractions of precursors

\begin{tabular}{lll}
\hline Mineral & $\begin{array}{l}\text { Precursor fraction } x_{p} \text { (est.) assuming reactivity of } \\
\mathrm{Al}_{2}(\mathrm{OH})_{2}^{4+}\end{array}$ & $\mathrm{Al}_{13}$ \\
\hline Bayerite & $9.210^{-6}$ & $7.610^{-2}$ \\
$\delta-\mathrm{Al}_{2} \mathrm{O}_{3}$ & $1.810^{-9}$ & $1.510^{-3}$ \\
Corundum & $1.210^{-8}$ & $1.010^{-4}$ \\
\hline
\end{tabular}

$x_{P}$ (est.) was calculated from Eq. (26) with the $R_{B}$ and $S_{1}$ values from Table 4. The microscopic rate constant $k_{e}$ in Eq. (26) was substituted by the rate constants for the decomposition of $\mathrm{Al}_{2}(\mathrm{OH})_{2}^{4+}$ and
$\mathrm{Al}_{13}$ from Table 3 


\section{Conclusions}

The key process in kaolinite dissolution in acidic solutions occurs preferentially at the Al surface centers rather then at the Si surface sites; the rate of dissolution is determined by protonation of both, the edge and the gibbsite surface of the kaolinite particles.

Polyvalent cations compete successfully with protons for the adsorption on active sites of the mineral surface resulting in lower dissolution rates (inhibition). The smallest surface concentration of polyvalent cations which leads to a significant inhibition may represent an upper limit for the mole fraction of active sites.

At $\mathrm{pH}=3$, the half live of surface sites at different aluminum (hydr)oxides varies from 2 years to 20 hours. The half life of the polynuclear $\mathrm{Al}_{13}$ complex is another order of magnitude smaller than that of the most labile among the solids (bayerite). These differences in half life may be explained qualitatively by the chemical structures of the Al centers.

Our comparative discussion of dissolution kinetics was based on the assumption that aluminum centers in similar coordinative environments show similar reactivities. The decomposition reactions of structurally well defined polynuclear $\mathrm{Al}$ species in homogeneous solutions were used as bench mark reactions. These allow estimates of possible concentration ranges of active sites at the mineral surfaces.

So far no experimental methods to determine the surface structure of minerals at the molecular level are available. Therefore our predictions of the mole fractions of dissolution-active sites remain speculative. However, the progress in the development of the atomic force microscope (AFM) opens the possibility to obtain images of the mineral-water interface with atomic resolution (Drake et al., 1989). In the future such new methods should be able to test the different hypotheses on the role of active sites in mineral dissolution.

\section{ACKNOWLEDGEMENTS}

We had the privilege to receive ideas, insights and inspiration from our teacher Werner Stumm. His enthusiasm and support catalyzed many rate limiting steps in our research. We thank you, Werner, for your optimism that the chemistry of complexation will shed light on complex heterogeneous processes. B. W. is grateful to James J. Morgan for many stimulating discussions and for the access to research facilities at the California Institute of Technology in Pasadena. We thank Paul W. Schindler for his helpful review.

\section{REFERENCES}

Aagaard, P., and H. C. Helgeson, 1982. Thermodynamic and kinetic constraints on reaction rates among minerals and aqueous solutions. I. Theoretical considerations. Am. J. Sci. 282:237-285.

Akitt, J. W., N. N. Greenwood, B. L. Khandelwal and G. D. Lester, 1972. ${ }^{27} \mathrm{Al}$ Nuclear magnetic resonance studies of the hydrolysis and polymerisation of the bexa-aquo-aluminum(III) cation. J. C. S. Dalton. 604-610. 
Amrhein, C., and D. L. Suarez, 1988. The use of a surface complexation model to describe the kinetics of ligand-promoted dissolution of anorthite. Geochim. Cosmochim Acta 52:2785-2793.

Avnir, D., D. Farin and P. Pfeifer, 1985. Surface geometric irregularity of particulate materials: The fractal approach. J. Colloid Interface Sci. 103:112-123.

Baes, C. F., and R. E. Mesmer, 1976. The Hydrolysis of Cations. New York, Wiley-Interscience.

Bennett, P. C., M. E. Melcer, D. I. Siegel and J. P. Hassett, 1988. The dissolution of quartz in dilute aqueous solutions or organic acids at $25^{\circ} \mathrm{C}$. Geochim. Cosmochim. Acta 52:1521-1530.

Bertsch, P. M., W. J. Layton and R. I. Bamhisel, 1986. Speciation of hydroxy-aluminum solutions by wet chemical and aluminum-27 NMR methods. Soil. Sci. Soc. Am. J. 50:1449-1454.

Blum, A. E., and A. C. Lasage, 1987. Monte Carlo simulations of surface reaction rate laws. In: W. Stumm (ed.), Aquatic Surface Chemistry. New York, Wiley-Intersience, pp. 255-292.

Blum, A. E., and A. C. Lasage, 1988. Role of surface speciation in the dissolution of minerals. Nature $331: 341-343$.

Bottero, J. Y., J. M. Cases, F. Fiessinger and J. E. Poirier, 1980. Studies of hydrolyzed aluminum chloride solutions. 1. Nature of aluminum species and composition of aqueous solutions. J. Phys.
Chem. 84:2933-2939.

Busenberg, E., and C. V. Clemency, 1976. The dissolution of feldspars at $25^{\circ} \mathrm{C}$ and 1 atm $\mathrm{CO}_{2}$ partial pressure. Geochim. Cosmochim. Acta 40:41-49.

Carroll-Webb, S. A., and J.V. Walther, 1988. A surface complex reaction model for the pHdependence of corundum and kaolinite dissolution rates. Geochim. Cosmochim. Acta 52:2609-
2623 .

Casey, W. H., H. R. Westrich and G. W. Arnold, 1988. Surface chemistry of labradorite feldspar reacted with aqueous solution at $\mathrm{pH}=2,3$ and 12. Geochim. Cosmochim. Acta 52:2795-2807.

Chou, L,, and R. Wollast, 1985. Steady-state kinetics and dissolution mechanisms of albite. Amer. J. Sci. 285:963-993.

Correns, C. W., and K. von Engelhardt, 1938. Neue Untersuchungen über die Verwitterung des Kalifeldspats. Chemie der Erde 1-22.

Correns, C. W., 1963. Experiments on the decomposition of silicates and discussion of chemical weathering. Clay and Clay Minerals 10:443-459.

Davis, J. A., R. O. James and J. O. Leckie, 1978. Surface ionization and complexation at the oxide/water interface. I. Computation of electrical double layer properties in simple electrolytes. J. Colloid Interface Sci. 63:480-499.

Drake, B. et al., 1989. Imaging crystals, polymers, and processes in water with the Atomic Force Microscope. Science 243:1586-1589.

Driscoll, C. T., J. P. Baker, J. J. Bisogni and C. L. Schofield, 1984. Aluminum speciation and equilibria in dilute acidic surface waters of the adirondack region of New York state. In: O.P. Bricker (ed.), Geological Aspects of Acid Deposition. Boston, Butterworth Publ., pp. 55-75.

Eggleton, R. A., and P. R. Buseck, 1980. High resolution electron microscopy of feldspar weathering. Clays and Clay Minerals 28:173-178.

Ferris, A.P., and W. B. Jepson, 1975. The exchange capacities of kaolinite and the preparation of homoionic clays. J. Colloid Interface Sci. 51:245-259.

Flegman, A. E., J.W. Goodwin and R. H. Ottewill, 1969. Rheological studies on kaolinite suspensions. Proc. Br. Ceram. Soc. 13:31-45.

Follett, E. A. C., 1965. The retention of amorphous, colloidal ferric hydroxide by kaolinite. J. Soil. Sci. 16:334-341.

Furrer, G., and W. Stumm, 1983. The role of surface coordination in the dissolution of $\delta-\mathrm{Al}_{2} \mathrm{O}_{3}$ in dilute acids. Chimia 37:338-341.

Furrer, G., and W. Stumm, 1986. The coordination chemistry of weathering I: Dissolution kinetics of $\delta-\mathrm{Al}_{2} \mathrm{O}_{3}$ and BeO. Geochim. Cosmochim. Act 50:1847-1860.

Guy, C., and J. Schott, 1989. Multisite surface reaction versus transport control during the hydrolysis of a complex oxide. Chem. Geol. (in press).

Hall, R. J., C. T. Driscoll, G. E. Likens and J. M. Pratt, 1985. Physical, chemical, and biological consequences of episodic aluminum additions to a stream. Limnol. Oceanogr. 30:212-220.

Helgeson, H. C., W. M. Murphy and P. Aagaard, 1984. Thermodynamic and kinetic constraints on reaction rates among minerals and aqueous solutions II. Rate constants, effective surface area and the hydrolysis of feldspar. Geochim. Cosmochim. Acta 48:2405-2432. 
Hem, J. D., 1983. Kinetics of dissolution and structure of aluminum hydroxide polymers. In: S. S. Augusthitis (ed.), Leaching and Diffusion in Rocks and their Weathering Products. Athens, Theophrastus Publications, pp. 51-62.

Holdren, G. R., and R. A. Berner, 1979. Mechanism of feldspar weathering. I. Experimental studies. Geochim. Cosmochim. Acta 43:1161-1171.

Holmes, L. P., D. L. Cole and E. M. Eyring, 1968. Kinetics of aluminum ion hydrolysis in dilute solutions. J. Phys. Chem. 72:301-304.

Hunt, J. P., and H. L. Friedman, 1983. Aquo complexes of metal ions. Progr. Inorg. Chem. 30:359 387.

Iler, R. K., 1973. Effect of adsorbed alumina on the solubility of amorphous silica in water. J. Colloid Interface Sci. 43:399-408.

Johansson, G., 1960. On the crystal structure of basic aluminium salts. Acta Chem. Scand. 14:771.

Kummert, R., and W. Stumm, 1980. Surface complexation of organic acids on hydrous $\gamma-\mathrm{Al}_{2} \mathrm{O}_{3} . \mathrm{J}$. Colloid Interface Sci. 75:373-385.

Lim, C. H., M. L. Jackson, R. D. Koons and P. A. Helmke, 1980. Kaolins: Sources of differences in cation-exchange capacities and caesium retention. Clays Clay Minerals 28:223-229.

Lutz, B., and H. Wendt, 1970. Fast ionic reaction in solution. VII. Kinetics of the fission and formation of the dimeric isopolybases $(\mathrm{FeOH})_{2}^{4+}$ and $(\mathrm{VOOH})_{2}^{2+}$. Ber. Bunsen-Gesell. 74:372380.

Motschi, H., and M. Rudin, 1984. ${ }^{27} \mathrm{Al}$ ENDOR study of $\mathrm{VO}^{2+}$ adsorbed on $\delta$-alumina. Colloid \& Polymer Sci. 262:579-583.

Petit, J. C., G. Della Mea, J. C. Dran, J. Schott and R. A. Berner, 1987. Mechanism of diopside dissolution from hydrogen depth profiling. Nature 325:705-706.

Pulfer, K., P. W. Schindler, J. C. Westall and R. Grauer, 1984. Kinetics and mechanism of bayerite $(\gamma$ $\left.\mathrm{Al}(\mathrm{OH})_{3}\right)$ in $\mathrm{HNO}_{3}-\mathrm{HF}$ solutions at $298.2^{\circ} \mathrm{C}$. J. Colloid Interface Sci. 101:554-564.

Schindler, P. W., B. Fürst, R. Dick and P. U. Wolf, 1976. Ligand properties of surface silanol groups I. Surface complex formation with $\mathrm{Fe}^{3+}, \mathrm{Cu}^{2+}, \mathrm{Cd}^{2+}$ and $\mathrm{Pb}^{2+}$. J. Colloid Interface Sci. 55:469475.

Schindler, P.W., and H. R. Kamber, 1968. Die Acidität von Silanolgruppen. Helv. Chem. Acta $51: 1781-1786$.

Schindler, P. W., P. Liechti and J. C. Westall, 1987. Adsorption of copper, cadmium and lead from aqueous solution to the kaolinite/water interface. Neth. J. Agr. Sci. 35:219-230.

Schindler, P.W., and W. Stumm, 1987. The surface chemistry of oxides, hydroxides and oxide minerals. In: W. Stumm (ed.), Aquatic Surface Chemistry. New York, Wiley-Interscience. pp. 83110.

Schott, J., S. Brantley, D. Cerar, C. Guy, M. Borcsik and C. Willaime, 1989. Dissolution kinetics of strained calcite. Geochim. Cosmochim. Acta 53:373-382.

Schott, J., and J. C. Petit, 1987. New evidence for the mechanisms of dissolution of silicate minerals. In: W. Stumm (ed.), Aquatic Surface Chemistry. New York, Wiley-Interscience, pp. 293-315.

Sigg, L., and W. Stumm, 1981. The interaction of anions and weak acids with the hydrous geothite ( $\alpha$ FeOOH) surface. Colloids Surfaces 2:107-117.

Sjöberg, E. L., 1978. Kinetics and mechanism of calcite dissolution in aqueous solutions at low temperatures. Stockholm Contrib. Geol. 32:1-96.

Stumm, W., C. P. Huang and S. R. Jenkins, 1970. Specific chemical interaction affecting the stability of dispersed systems. Croat. Chem. Acta 42:223-245.

Stumm, W., and J. J. Morgan, 1981. Aquatic Chemistry, New York, Wiley.

Stumm, W., B. Wehrli and E. Wieland, 1987. Surface complexation and its impact on geochemical kinetics. Croat. Chem. Acta 60:429-456.

Thiessen, P. A., 1942. Wechselseitige Adsorption von Kolloiden. Z. Elektrochem. 48:675-681.

Thompson, D. W., and S. Hayward, 1987. An electron microscope study of the surface electrical properties of silicate clay crystals. Colloids Surf. 28:315-325.

van Olphen, H., 1977. An Introduction to Clay Colloid Chemistry. New York, Wiley-Intersciences.

Wehrli, B., 1989. Monte Carlo simulations of surface morphologies during mineral dissolution. J. Coll. Interf. Sci. 132:230-242

Wehrli, B., and W. Stumm, 1989. Vanadyl in natural waters: Adsorption and hydrolysis promote oxygenation. Geochim. Cosmochim. Acta 53:69-77. 
Weiss, A., 1959. Über das Kationenaustauschvermögen der Tonmineralien III. Der Kationenaustausch bei Kaolinit. Z. anorg. allg. Chemie 299:92-103.

Wells, A. F., 1975. Structural Inorganic Chemistry. Oxford, Claredon Press.

Wersin, P., L. Charlet, R. Karthein and W. Stumm, 1989. From adsorption to precipitation: Sorption of $\mathrm{Mn}^{2+}$ on $\mathrm{FeCO}_{3}(\mathrm{~s})$. Geochim. Cosmochim. Acta 53:2787-2796

Westall, J., and H. Hohl, 1980. Comparison of electrostatic models for the oxide/water interface. Adv. Colloid Interface Sci. 12:265-294.

Wieland, E., 1988. Die Verwitterung schwerlöslicher Mineralien - ein koordinationschemischer Ansatz zur Auflösungskinetik. Diss. ETH Nr. 8532.

Wieland, E., B. Wehrli and W. Stumm, 1988. The coordination chemistry of weathering: III. A generalization on the dissolution rates of minerals. Geochim. Cosmochim. Acta 52:1969-1981.

Williams, D. J. A., and K. P. Williams, 1978. Electrophoresis and zeta potentials of kaolinite. J. Colloid Interface Sci. 65:79-87.

Wirth, G. S., and J. M. Gieskes, 1979. The initial kinetics of the dissolution of vitreous silica in aqueous media. J. Colloid Interface Sci. 68:492-500.

Wollast, R., 1967. Kinetics on the alteration of $K$-feldspars in buffered solutions at low temperature. Geochim. Cosmochim. Acta 31:635-648.

Yasunaga, T., and T. Ikeda, 1986. Adsorption-desorption kinetics at the metal-oxide-solution interface studied by relaxation methods. In: J. A. Davis and K. F. Hayes (eds.), Geochemical Processes at Mineral Surfaces. Washington, ACS Symposium Series 323, pp. 230-253.

Yates, D. E., S. Levine and T. W. Healy, 1974. Site-binding model of the electrical double layer at the oxide/water interface. J. Chem. Soc., Faraday Trans. I. 70:1807-1818.

Zinder, B., G. Furrer and W. Stumm, 1986. The coordination chemistry of weathering: II. Dissolution of Fe(III) oxides. Geochim. Cosmochim. Acta 50:1861-1869.

Received 11 August 1989. 